\title{
Variability of the infrared complex refractive index of African mineral dust: experimental estimation and implications for radiative transfer and satellite remote sensing
}

\author{
C. Di Biagio ${ }^{1}$, H. Boucher ${ }^{2}$, S. Caquineau ${ }^{2}$, S. Chevaillier ${ }^{1}$, J. Cuesta ${ }^{1}$, and P. Formenti ${ }^{1}$ \\ ${ }^{1}$ LISA, UMR CNRS 7583, Université Paris Est Créteil et Université Paris Diderot, Institut Pierre Simon Laplace, \\ Créteil, France \\ ${ }^{2}$ IPSL/LOCEAN, UMR 7159-IRD-CNRS-UPMC-MNHN, Institut de Recherche pour le Développement, Bondy, France \\ Correspondence to: C. Di Biagio (claudia.dibiagio@lisa.u-pec.fr)
}

Received: 29 January 2014 - Published in Atmos. Chem. Phys. Discuss.: 28 April 2014

Revised: 2 September 2014 - Accepted: 11 September 2014 - Published: 22 October 2014

\begin{abstract}
Experimental estimations of the infrared refractive index of African mineral dust have been retrieved from laboratory measurements of particle transmission spectra in the wavelength range $2.5-25 \mu \mathrm{m}$. Five dust samples collected at Banizoumbou (Niger) and Tamanrasset (Algeria) during dust events originated from different Western Saharan and Sahelian areas have been investigated. The real $(n)$ and imaginary $(k)$ parts of the refractive index obtained for the different dust samples vary in the range 1.1-2.7 and 0.05-1.0, respectively, and are strongly sensitive to the mineralogical composition of the particles, especially in the 8-12 and 17-25 $\mu \mathrm{m}$ spectral intervals. Dust absorption is controlled mainly by clays (kaolinite, illite, smectite) and, to a lesser extent, by quartz and calcium-rich minerals (e.g. calcite, gypsum). Significant differences are obtained when comparing our results with existing experimental estimations available in the literature, and with the values of the OPAC (Optical Properties of Aerosols and Clouds) database. The different data sets appear comparable in magnitude, with our values of $n$ and $k$ falling within the range of variability of past studies. However, literature data fail in accurately reproducing the spectral signatures of the main minerals, in particular clays, and they significantly overestimate the contribution of quartz. Furthermore, the real and the imaginary parts of the refractive index from some literature studies are found not to verify the KramersKronig relations, thus being theoretically incorrect. The comparison between our results, from western Africa, and literature data, from different locations in Europe, Africa, and the Caribbean, nonetheless, confirms the expected large vari-
\end{abstract}

ability of the dust infrared refractive index. This highlights the necessity for an extended systematic investigation of dust properties at infrared wavelengths.

For the five analysed dust samples, aerosol intensive optical properties relevant to radiative transfer (mass extinction efficiency, $k_{\text {ext }}$, single scattering albedo, $\omega$, and asymmetry factor, $g$ ) have been calculated, by using the Mie theory, based on the estimated refractive index and measured particle size distribution. The optical properties show a large sample-to-sample variability, with $k_{\text {ext }}, \omega$, and $g$ varying in the range $0.05-0.35,0.25-1.0$, and $0.05-0.75$. This variability is expected to significantly impact satellite retrievals of atmospheric and surface parameters (e.g. from the Infrared Atmospheric Sounding Interferometer, IASI) and estimates of the dust radiative forcing.

\section{Introduction}

Mineral dust is one of the most abundant aerosol species in the atmosphere and strongly contributes to the total aerosol content (Textor et al., 2007; Huneeus et al., 2012). The arid and semiarid regions of West Africa, i.e. the Sahara and the Sahel, account for more than $60 \%$ of the total annual dust emission, and are by far the most significant sources of mineral dust at the global scale (Prospero et al., 2002; Laurent et al., 2008; Ginoux et al., 2012). Once emitted, African dust is transported for thousands of kilometres across the Atlantic Ocean (e.g. Ben-Ami et al., 2009, 2010) and the 
Mediterranean Basin (e.g. Israelevich et al., 2002), thus affecting the environment at intercontinental distances.

Mineral dust directly affects the planetary radiative balance by absorption and scattering of radiation (Sokolik and Toon, 1996). Due to their high atmospheric load, dust aerosols are observed to exert a significant radiative effect both close to source regions and in transport areas (Haywood et al., 2003; Highwood et al., 2003; Di Biagio et al., 2010). As a consequence of the effect on radiation, mineral dust impacts the atmospheric thermal structure and stability (Kishcha et al., 2003; Heinold et al., 2008), with possible effects on cloud formation and properties (Rosenfeld et al., 2001; Klüser and Holzer-Popp, 2010), as well as on atmospheric photochemical reactions (Casasanta et al., 2011). The implications on the hydrological cycle, in particular, are of great relevance for water-stressed semiarid areas, as it is the case of the Sahel, mainly in relation to possible feedback mechanisms on dust emission in these regions (Carlsaw et al., 2010).

Due to its characteristic mineralogical composition and extended particle size spectrum (from tenths of nanometres to tenths of micrometres), mineral dust effectively interacts with both the solar and the terrestrial infrared radiation fields (Ackerman and Chung, 1992; Hsu et al., 2000; Brindley and Russell, 2009). In terms of magnitude, the instantaneous solar effect is considerably larger than the infrared one, which generally becomes relevant only for very high dust amounts (e.g. Slingo et al., 2006). However, while the solar contribution is effective only during daytime, the infrared contribution acts throughout the $24 \mathrm{~h}$; thus, on a daily basis it may compensate for a large fraction of the diurnal shortwave perturbation (e.g. di Sarra et al., 2011). The infrared contribution needs therefore to be taken into account in order to estimate the whole dust radiative effect.

The interaction of atmospheric dust with infrared radiation has also been shown to significantly affect the interpretation of remote sensing data. In particular, several key climate parameters, such as the atmospheric temperature profile, sea surface temperature, and greenhouse gases concentration, are derived from satellite measurements over narrowband infrared channels (MODIS, Moderate Resolution Imaging Spectroradiometer; SEVIRI, Spinning Enhanced Visible and Infrared Imager; AVHRR, Advanced Very High Resolution Radiometer; HIRS, High-resolution Infrared Radiation Sounder; AIRS, Atmospheric Infrared Sounder; and IASI, Infrared Atmospheric Sounding Interferometer). Misinterpretations of the data occur when the infrared radiative effect of dust is not accurately taken into account within satellite inversion algorithms (e.g. Ackerman, 1997; Sokolik, 2002; DeSouza-Machado et al., 2006). However, the dust infrared signature obtained in satellite data, especially in the $8-12 \mu \mathrm{m}$ window region, is used to detect the presence and estimate the properties of dust from space (Legrand et al., 2001; Pierangelo et al., 2004; Klüser et al., 2011; Banks and Brindley, 2013; Capelle et al., 2014).
Still, very large uncertainties persist in the estimation of the dust infrared radiative effect (Haywood et al., 2005; Balkanski et al., 2007; Bierwirth et al., 2009). One of the main causes for this is the poor knowledge of the dust optical properties in this region of the spectrum (e.g. Wang et al., 2006). Dust infrared optical properties cannot be directly measured by in situ instruments, and also their estimation based on ground-based or satellite remote sensing observations is difficult, due to the fact that the aerosol signature is partly covered by that of main atmospheric constituents (water vapour, $\mathrm{CO}_{2}$ ) and that a priori knowledge of the investigated optical properties is often required by inversion algorithms. Thus, dust infrared optical properties are generally estimated through an alternative approach, which consists in calculating them based on the knowledge of the physicochemical properties of particles, i.e. composition, size distribution, and shape (Levin and Lindberg, 1979; Highwood et al., 2003).

In this sense, the complex refractive index, $m=n-i k$, the parameter linking the physico-chemical and the optical properties of aerosols, remains a major unknown (e.g. Sokolik et al., 1993; Claquin et al., 1998).

The complex refractive index of dust is mainly controlled by particle mineralogical composition (Patterson, 1981; Sokolik et al., 1998). Dust is composed of several minerals, such as clays (kaolinite, illite, smectite, chlorite), quartz, calcium-rich carbonates (calcite, dolomite) and sulfates (gypsum), feldspars (orthose, albite), and iron and titanium oxides, each characterized by specific lattice vibrational-rotational transitions, therefore by their own spectral refractive index in the infrared (Sokolik and Toon, 1999). Consequently, the magnitude and the spectral dependence of the complex refractive index of dust depend on the abundance and state of mixing (internal or external) of its main constituents (e.g. Mishchenko et al., 2004). Due to the diverse soil mineralogy of the different source areas (Claquin et al., 1999), the composition of dust aerosols varies depending on the region of origin (e.g. Caquineau et al., 2002). The proportion between the different minerals at emission also critically depends on the surface wind speed of erosion, which also determines their size distribution (Gomes and Gillette, 1993; Marticorena and Bergametti, 1995). Quartz, feldspars, and calcium-rich species are generally more abundant in the coarse mode component, while clays dominate the fine fraction (e.g. Pye, 1987; Kandler et al., 2009). The mineralogical composition of dust then changes rapidly after emission mainly as a consequence of the progressive loss of coarse particles due to gravitational settling (Schütz et al., 1981; Maring et al., 2003). This process reduces the abundance of quartz, feldspars, and calciumrich species in the dust aerosol, thus yielding particles richer in clays. Also, when travelling over marine or polluted environments, the composition of dust may be additionally modified due to the interaction with other aerosol types (e.g. sea salts, soot) or atmospheric gases (e.g. nitrates, sulfates) 
(Formenti et al., 2011). As a consequence of all these processes, the complex refractive index of mineral dust is expected to vary as a function of the source region and during atmospheric transport. The complete characterization of this variability is necessary to evaluate the magnitude of the dust radiative effect along its whole atmospheric life cycle.

A very few number of studies, from a limited number of geographical locations worldwide (e.g. Germany, Barbados, Niger), have investigated the complex refractive index of dust aerosols at infrared wavelengths (Volz, 1972, 1973; Fisher, 1976; Patterson, 1981; Fouquart et al., 1987; see also Sokolik et al., 1993, 1998, and references therein). Hence, to date, the natural variability of the dust infrared refractive index is not represented. Moreover, some degree of uncertainties remains on the accuracy and representativeness of these few data. In all of these studies the refractive index of dust is estimated by means of the spectroscopy pellet technique. This approach consists in dispersing the aerosol particles in a matrix of transparent material, e.g. potassium bromide $(\mathrm{KBr})$, which is then pressed to form a homogeneous pellet. A typical fraction of $0.1 \%$ of dust particles is dispersed in a total of 100-300 mg of KBr. The reflectance or transmission spectrum of the pellet is then measured and analysed by means of an appropriate optical theory to retrieve the complex refractive index of the particles. The pellet technique presents however several limitations which means it is not fully adapted to investigate aerosols. At first, this technique requires one to manipulate the aerosol sample, mixing it with $\mathrm{KBr}$, and then to press the mixture to form the pellet. These operations may modify the physico-chemical properties of the particles, thus reducing the representativeness of the analysed samples compared to natural airborne conditions. In particular, the aerosol size distribution, as well as the morphology of the particles, may be affected by these modifications mainly due to the pressing during pellet production. Moreover, the fact of dispersing a very small quantity of aerosol $(0.1 \%)$ in the $\mathrm{KBr}$ matrix determines a strong suppression of the aerosol scattering signal, which becomes almost negligible compared to that from the matrix itself. As a consequence, mainly the absorption component of the extinction is measured with the pellet technique, with a strong underestimation of the scattering fraction. This aspect is particularly important for dust particles, for which scattering is estimated to significantly contribute to the atmospheric infrared extinction (Dufresne et al., 2002). Despite these limitations and uncertainties, nonetheless, pellet spectroscopy data represent nowadays the only available references for dust infrared optical properties, and are used as the main basis for global aerosol databases such as OPAC (Optical Properties of Aerosols and Clouds; Hess et al., 1998) and GADS (Global Aerosol Data Set; Koepke et al., 1997).

In this study we apply the spectroscopy pellet technique to provide new experimental estimates of the infrared complex refractive index of dust aerosols. Natural particle samples from Western Sahara and the Sahel, some of the strongest sources at the global scale (Ginoux et al., 2012), have been considered. The paper has two main objectives: (i) to test the sensitivity of the dust infrared refractive index to the physicochemical properties of the particles, in particular to the mineralogy. We want to show that, also at the small scale (western Africa), there is a significant variability of the dust refractive index as a function of particle properties that past studies are only in part able to detect; (ii) to show the importance of this variability on radiative forcing calculations and satellite remote sensing. The dust refractive index has been estimated in this study from spectroscopy pellet transmission measurements by applying an experimental procedure and a retrieval scheme mostly consistent with those of past literature studies (see also Sect. 2.1). We have made this choice, aware of the limitations and uncertainties of the spectroscopy technique discussed above, to simplify the comparison between past and new data, thus allowing for an easier evaluation of the dust refractive index variability.

Dust samples analysed here have been collected during the AMMA 2006 campaign (African Monsoon Multidisciplinary Analysis; Redelsperger et al., 2006) at the ground-based supersites of Banizoumbou $\left(13.5^{\circ} \mathrm{N}, 2.6^{\circ} \mathrm{E}, 250 \mathrm{~m}\right.$ above sea level), located in a remote area $\sim 60 \mathrm{~km}$ east of Niamey in Niger (Rajot et al., 2008), and Tamanrasset $\left(22.8^{\circ} \mathrm{N}, 5.5^{\circ} \mathrm{E}\right.$, $1370 \mathrm{~m}$ above sea level), in the heart of the Hoggar Massif in southern Algeria (Cuesta et al., 2008). Five different dust cases were selected based on their different origin and mineralogical composition: three from the Banizoumbou site (sample ID SOP0-47, SOP1-8, and SOP1-17; SOP - special observing period), and two from Tamanrasset (sample ID N32 and N93). As here we want to focus on the refractive index variability near source regions, the five cases have been chosen to be representative of local emission episodes or of dust at most after 1-2 days of atmospheric transport. A summary of the main information for the selected Banizoumbou and Tamanrasset dust events is reported in Table 1. A more detailed discussion of the five dust episodes and identification of their different source regions is provided in Appendix A.

The paper is organized as follows: in Sect. 2 we present the measurements used in this analysis, the experimental method, and the main algorithm for complex refractive index estimation. The physico-chemical properties obtained for the considered samples are discussed in Sect. 3. Section 4 is then dedicated to the presentation and discussion of the spectroscopy measurements and complex refractive index results. The effect of the variability of the refractive index and size distribution on the optical properties of dust, as well as its possible implications on radiative transfer and satellite remote sensing, is investigated in Sect. 5. The main conclusions of this study are discussed in Sect. 6. 
Table 1. Main characteristics of the five dust cases selected in this study: the sample ID, the measurement site, the date and time of beginning and end of the observed dust event, the associated filter sampling time interval within the event, and the identified dust source region. The mean aerosol optical depth $(\tau)$ at $0.50 \mu \mathrm{m}$ and the Ångstrom exponent ( $\alpha$, calculated between 0.44 and $0.87 \mu \mathrm{m})$ obtained from AERONET (Aerosol Robotic Network) measurements during filter sampling for the different cases are also reported; no data are available for the SOP18 , when the solar zenith angle at the start of the sampling was $>70^{\circ}$, and for the SOP1-17, which corresponds to night-time data (UTC, Universal Time Coordinated).

\begin{tabular}{|c|c|c|c|c|c|c|}
\hline Sample ID & Measurement site & $\begin{array}{l}\text { Dust event period: } \\
\text { beginning-end (date and time in UTC) }\end{array}$ & $\begin{array}{l}\text { Dust sampling period within the event: } \\
\text { beginning-end (date and time in UTC) }\end{array}$ & Dust source & $\begin{array}{c}\tau_{0.50 \mu m} \\
\text { (from AERONET) }\end{array}$ & $\begin{array}{c}\alpha_{0.44-0.87 \mu m} \\
\text { (from AERONET) }\end{array}$ \\
\hline SOP0-47 & Banizoumbou & 09/02/2006 01:50-10/02/2006 02:20 & 09/02/2006 09:28-09/02/2006 16:32 & $\begin{array}{l}\text { Algeria - Niger and Mali - } \\
\text { Niger frontier areas }\end{array}$ & 0.52 & 0.15 \\
\hline SOP1-8 & Banizoumbou & 04/06/2006 16:52-04/06/2006 17:36 & 04/06/2006 16:52-04/06/2006 17:36 & Local erosion event & - & - \\
\hline SOP1-17 & Banizoumbou & 08/06/2006 22:33-09/06/2006 06:40 & 08/06/2006 22:33-09/06/2006 06:40 & Local erosion event & - & - \\
\hline N32 & Tamanrasset & $21 / 07 / 2006 \sim 21: 00-27 / 07 / 2006 \sim 18: 00$ & 23/07/2006 09:55-24/07/2006 11:41 & $\begin{array}{l}\text { Eastern part of the Algeria - } \\
\text { Niger frontier area }\end{array}$ & 1.30 & 0.06 \\
\hline N93 & Tamanrasset & $05 / 10 / 2006 \sim 00: 00-07 / 10 / 2006 \sim 12: 00$ & 05/10/2006 13:09-07/10/2006 10:40 & Algerian Atlas & 0.48 & 0.11 \\
\hline
\end{tabular}

\section{Measurements and methods}

Dust aerosol samples have been collected at the two sites of Banizoumbou and Tamanrasset on $47 \mathrm{~mm}$ polycarbonate Nuclepore filters (nominal pore size $0.4 \mu \mathrm{m}$ ). The sampling time for the different cases (see Table 1) varied between a few hours to 1-2 days, depending on the aerosol concentration and the duration of the event. Dust particles deposited on filters have been analysed to obtain their bulk mineralogical composition. Then the infrared transmission spectra have been measured on the samples of collected dust to estimate their complex refractive index. The number size distribution of dust particles in the diameter range $0.3-20 \mu \mathrm{m}$ was measured during filter sampling by means of a Grimm optical particle counter (OPC, model 1.108). Full details on spectroscopy measurements and algorithm for complex refractive index estimation, dust filter chemical analyses, and procedures for size distribution data corrections are provided in the next paragraphs.

\subsection{Infrared spectroscopy and dust complex refractive index estimation}

Transmittance spectra $(T)$ of collected dust particles have been recorded in the wavelength range $2.5-25 \mu \mathrm{m}(4000$ $400 \mathrm{~cm}^{-1}$ wave number) at $2 \mathrm{~cm}^{-1}$ resolution by means of a Bruker Optics Equinox 55 FT-IR spectrometer. The instrument uses a Globar source, with a $\mathrm{KBr}$ beamsplitter and a deuterated triglycine sulfate (DTGS) detector. The infrared transmission spectroscopy has been performed by means of the usual pellet technique (i.e. Volz, 1972; Mooney and Knacke, 1985) using $\mathrm{KBr}$ as transparent matrix in which dust grains have been dispersed.

Dust particles collected on Nuclepore membranes need to be extracted from filters to mix with the $\mathrm{KBr}$ powder and then to produce the pellets. As discussed in the Introduction, the manipulation of dust particles is a delicate operation and it should be achieved by avoiding as much as possible contaminations or modifications of the sample. We tested different procedures to optimize dust extraction and $\mathrm{KBr}$ mixing. Our best obtained experimental protocol is described in the following:

i. suspension of dust particles in ethanol solution. To allow dust particles to detach from the filter membranes, filters are immersed, dust-loaded face downward, in 10$15 \mathrm{~mL}$ of ethanol and shaken for $\sim 5-10 \mathrm{~min}$ at ultrasonic frequencies. The ultrasonic shaking procedure is repeated 2-3 times, until the aerosol has completely detached from the filter.

ii. Separation of dust and ethanol. The dust-ethanol suspension is centrifuged at a speed of $11000 \mathrm{rpm}$ (revolutions per minute) for $\sim 1 \mathrm{~h}$, thus permitting an effective separation between the liquid (ethanol) and the solid (dust) phases. After centrifugation the dust-ethanol solution is left in vertical position for 1 day to sediment dust particles which had remained in suspension. At this point, having the liquid and solid phases well separated, $\sim 95 \%$ of ethanol is removed by pipe aspiration, while the remaining $\sim 5 \%$ is left to evaporate for 1 day.

iii. Dilution of dust particles in the $\mathrm{KBr}$ matrix. Once extracted and transferred to a glass tube, dust particles are weighed and then diluted in a $\mathrm{KBr}$ matrix. A highquality, pure potassium bromide (ACROS Organics IR grade) is used. The mass of $\mathrm{KBr}$ is set to obtain a total of $0.1 \%$ of dust in the mixture. Dust and $\mathrm{KBr}$ are weighed by means of a Sartorius microbalance (model LE225D) whose maximum sensitivity is $10 \mu \mathrm{g}$. The dust- $\mathrm{KBr}$ mixture is then mechanically shaken for about $10 \mathrm{~min}$ to create a homogeneous mixing. The obtained dust$\mathrm{KBr}$ samples and the pure $\mathrm{KBr}$ are placed in the oven to dry at the temperature of $100^{\circ} \mathrm{C}$ for $\sim 12 \mathrm{~h}$. Putting the samples in the oven does not modify the dust mineralogical composition, as at these temperatures the main effect is water evaporation.

iv. Pellet production. Each of the five dust- $\mathrm{KBr}$ mixture samples is softly grounded in agate mortar, in order to slightly change the size of dust grains, and then is 
pressed under vacuum at the pressure of $\sim 10 \mathrm{tcm}^{-2}$ for $1-2 \mathrm{~min}$ to form a thin pellet. About $150 \mathrm{mg}$ of powder is needed to create a homogeneous pellet of $13 \mathrm{~mm}$ diameter $\left(1.33 \mathrm{~cm}^{2}\right.$ surface $)$ and $<1 \mathrm{~mm}$ thickness. Three pure $150 \mathrm{mg} \mathrm{KBr}$ pellets are also produced. Then all the pellets are put in the oven at $100^{\circ} \mathrm{C}$ for about $1-2 \mathrm{~h}$ until they are used for transmission spectroscopy measurements. This is done to avoid as much as possible water vapour absorption, in particular by the highly hygroscopic $\mathrm{KBr}$. We should expect, as already mentioned, that some of the dust properties, such as the size distribution, aggregation state, or also the morphology of the particles, may partly change during the pellet production, thus affecting the representativeness of the analysed sample compared to airborne conditions. It should be pointed out, however, that the estimation of the effects of these modifications on the measured spectra is very difficult, and a certain degree of uncertainty on this aspect remains not quantified. All the laboratory operations we have described here are accomplished in clean conditions, i.e. working in a permanently ventilated room, and manipulating the samples in a laminar flow bench.

Spectroscopic measurements have been performed on the five dust- $\mathrm{KBr}$ and the three pure $\mathrm{KBr}$ samples. Pellets were placed in the spectrometer chamber purged of $\mathrm{CO}_{2}$ gas and $\mathrm{H}_{2} \mathrm{O}$ vapour. A total of 20 and 40 scans were averaged to produce the dust- $\mathrm{KBr}$ and the pure $\mathrm{KBr}$ spectra, respectively. The three spectra of pure $\mathrm{KBr}$ have been averaged and used to correct the baseline of dust-KBr spectra. This correction allows removing the signal due to the water vapour or other gases possibly absorbed on the pellet by $\mathrm{KBr}$. Once corrected for the baseline signal, the dust-KBr spectra have been smoothed by performing a nine-point running average.

Starting from the measured dust- $\mathrm{KBr}$ transmission spectra, the real $(n)$ and the imaginary $(k)$ parts of the dust refractive index have been estimated following the procedure already applied by various authors to investigate Martian dust (Orofino et al., 1998; Marzo et al., 2004; Marra et al., 2005). The hypotheses at the base of our retrieval scheme, as will be discussed in the following, are consistent with the main assumptions made in most past studies on dust aerosols available in the literature (e.g. Volz 1972, 1973; Fouquart et al., 1987).

Based on the Beer-Bouguer-Lambert law, the spectral transmittance, $T(\lambda)$, through a thin section of a specific medium is given by

$\ln \left(\frac{1}{T(\lambda)}\right)=\alpha_{\mathrm{ext}}(\lambda) x$

where $\alpha_{\text {ext }}(\lambda)$ is the spectral extinction coefficient of the medium and $x$ the path length of radiation. In our case the medium is a pellet composed of a matrix of transparent material $(\mathrm{KBr})$ in which a small amount of grain particles (dust) are uniformly dispersed. $\alpha_{\text {ext }}(\lambda)$ may thus be written as the product of the grain extinction cross section, $C_{\text {ext }}(\lambda)$, by the $f / V$ ratio, where $f$ is the volume fraction of grain particles in the sample and $V$ is the volume of a single particle (Bohren and Huffman, 1983). We can imagine grain particles to be compressed within the pellet in a homogeneous slab $(f=1)$ of thickness $d=\frac{M}{\rho S}$, with $M$ the total grain mass contained in the pellet, $\rho$ the density of the grain material, and $S$ the surface of the pellet, to obtain

$\alpha_{\mathrm{ext}}(\lambda)=\frac{C_{\mathrm{ext}}(\lambda)}{V}=\frac{3}{4} \frac{Q_{\mathrm{ext}}(\lambda)}{a}$,

where $Q_{\text {ext }}(\lambda)$ is the grain extinction efficiency and $a$ the particle radius. The dust density is set at $2.5 \mathrm{~g} \mathrm{~cm}^{-3}$ for all the samples. This value is chosen approximately at the mean of the range of desert dust densities as reported in the literature, i.e. $2.1-2.75 \mathrm{~g} \mathrm{~cm}^{-3}$ (i.e. Maring et al., 2000; Winfield, 2000; Iwasaka et al., 2003; Reid et al., 2003; Fratini et al., 2007).

In case extinction is dominated by absorption, $Q_{\text {ext }} \sim Q_{\text {abs }}$, as it can be assumed at infrared wavelengths for dust in pellets, we can write explicitly the $Q_{\text {abs }}(\lambda) / a$ ratio as a function of the measured transmittance as

$\frac{Q_{\mathrm{abs}}(\lambda)}{a}=\frac{4}{3} \frac{\rho S}{M} \ln \left(\frac{1}{T(\lambda)}\right)$.

For very small grains ( $a \ll \lambda$, i.e. the Rayleigh limit) embedded in a matrix of transparent material, the ratio between the absorption efficiency and the particle radius can be written following the Mie theory for Rayleigh spherical particles as (Bohren and Huffmann, 1983)

$\frac{Q_{\mathrm{abs}}(\lambda)}{a}=\frac{8 \pi}{\lambda} \sqrt{\varepsilon_{\mathrm{m}}} \operatorname{Im}\left(\frac{\bar{\varepsilon}(\lambda)-1}{\bar{\varepsilon}(\lambda)+2}\right)$,

where $\varepsilon_{\mathrm{m}}=\left(n_{0, \mathrm{~m}}\right)^{2}$ is the real dielectric function of the matrix, with $n_{0, \mathrm{~m}}$ the real component of the $\mathrm{KBr}$ refractive index, and $\bar{\varepsilon}(\lambda)$ the dielectric function of the grain material relative to the matrix. The value of $n_{0, \mathrm{~m}}$ for $\mathrm{KBr}$ has been set at 1.54, constant in the infrared spectral range considered, as also reported in Orofino et al. (1998), and thus $\varepsilon_{\mathrm{m}}=2.37$. The verification of the Rayleigh limit $a \ll \lambda$ has been tested for our dust samples using co-located measurements of the particle number size distribution (Grimm data shown in Fig. 1 and discussed in the next sections). At the wavelengths of 10 and $20 \mu \mathrm{m}$, the condition $a / \lambda<0.1$, which can be considered satisfactory to verify the Rayleigh limit, is fulfilled on average by the 94 and $98 \%$ of particles (in number), respectively. Moreover, in our formulation (Eq. 4) we assume dust particles to have a spherical shape, and thus to be described by the Mie theory. Taking into account particle non-sphericity would require a much more complex retrieval scheme. We have decided to neglect this effect at this stage, thus maintaining retrieval conditions which 


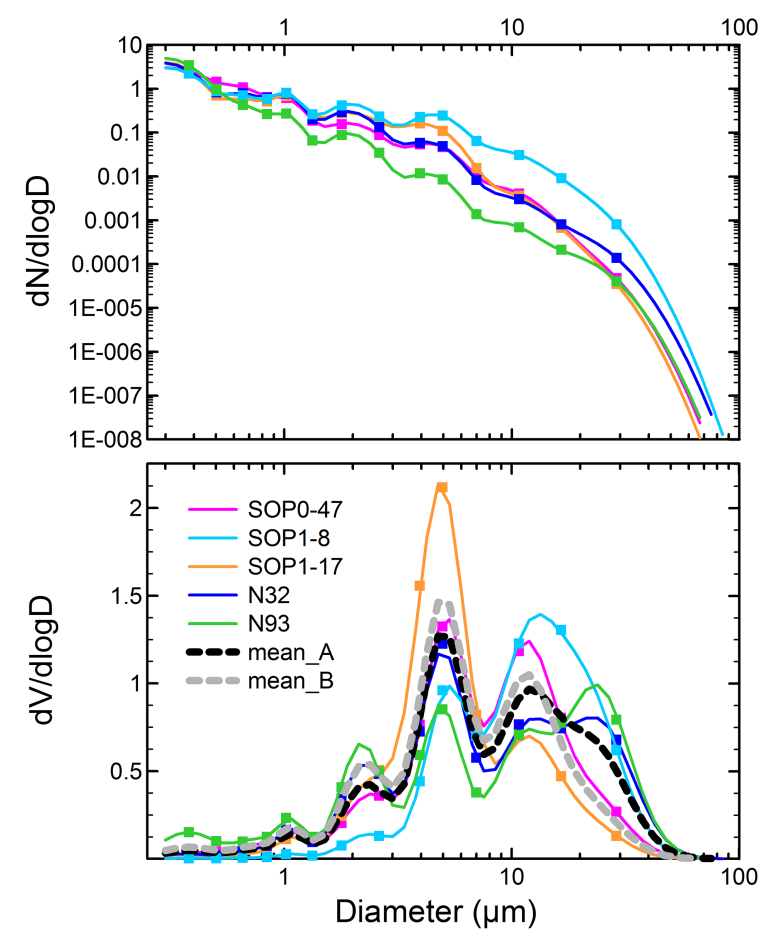

Figure 1. Particle number $(\mathrm{d} N / \mathrm{d} \log D)$ and volume $(\mathrm{d} V / \mathrm{d} \log D)$ size distributions (normalized with respect to the total number and total volume of particles, respectively) obtained for the five selected dust events. The dots indicate the GRIMM measured values, while the lines are the multimodal lognormal fit data. Black and grey dashed lines are the averages of the volume size distributions for the five samples obtained including (mean_A, black dashed line) and excluding (mean_B, grey dashed line) the largest mode at $\sim 25 \mu \mathrm{m}$ for N32 and N93 samples. The legend in the bottom panel identifies the line styles used in the plot.

are similar to those of previous literature studies on the dust refractive index.

The dielectric function in Eq. (4) may be written using the Clausius-Mossotti relation as the sum of $N$ Lorentzian harmonic oscillators:

$\frac{\bar{\varepsilon}(\omega)-1}{\bar{\varepsilon}(\omega)+2}=\frac{\bar{\varepsilon}_{\mathrm{v}}(\omega)-1}{\bar{\varepsilon}_{\mathrm{V}}(\omega)+2}+\left[\sum_{j=1}^{N} \frac{F_{j}}{\omega_{j}^{2}-\omega^{2}-i \gamma_{j} \omega}\right]$,

where $\omega$ is the angular frequency of radiation $(\omega=2 \pi \mathrm{c} / \lambda$, $\left.\mathrm{s}^{-1}\right), c$ is the velocity of light in vacuum, and $\bar{\varepsilon}_{\mathrm{v}}$ is the real dielectric function of the grain material relative to the matrix in the limit of high frequencies; i.e. at visible wavelengths, $\bar{\varepsilon}_{\mathrm{v}}=\left(\frac{\varepsilon_{\mathrm{g}}}{\varepsilon_{\mathrm{m}}}\right)_{\text {vis }}$ with $\varepsilon_{\mathrm{g}}=\left(n_{0, \mathrm{~g}}\right)_{\text {vis }}^{2}$ and $\varepsilon_{\mathrm{m}}=\left(n_{0, \mathrm{~m}}\right)_{\text {vis }}^{2}$, the square of the real components of the refractive index at visible wavelengths for the grain material and the matrix, respectively. $\left(n_{0, \mathrm{~m}}\right)_{\text {vis }}$ and $\left(n_{0, \mathrm{~g}}\right)_{\text {vis }}$ have been set at 1.57 and 1.53 , respectively, as the mean of the values reported in literature for $\mathrm{KBr}$ (e.g. Orofino et al., 1998) and African dust (Osborne et al., 2008; Petzold et al., 2009; McConnell et al., 2010; Klaver et al., 2011). Our choice of $\left(n_{0, \mathrm{~g}}\right)_{\mathrm{vis}}=1.53$ is also in agreement with the values reported by most of past literature studies on the dust infrared refractive index (see data shown in Fig. 7). $\omega_{j}, \gamma_{j}$, and $F_{j}$ are the three fundamental parameters characterizing the $j$ th oscillator and, in particular, $\omega_{j}$ is the eigenfrequency, $\gamma_{j}$ is the damping factor, and $F_{j}$ is a quantity related to the plasma frequency strength, $\omega_{\mathrm{p}, j}$, and the oscillator strength, $\mathrm{f}_{j}$, through the relation $F_{j}=\frac{1}{3} f_{j} \omega_{\mathrm{p}, j}^{2}$. By combining Eqs. (4) and (5), we have

$\frac{Q_{\mathrm{abs}}(\omega)}{a}=\frac{4 \omega}{c} \sqrt{\varepsilon_{\mathrm{m}}}\left[\sum_{j=1}^{N} \frac{F_{j} \gamma_{j} \omega}{\left(\omega_{j}^{2}-\omega^{2}\right)^{2}+\gamma_{j}^{2} \omega^{2}}\right]$.

Starting from the transmission measurements and by applying Eq. (3) an experimental estimation of the ratio $Q_{\text {abs }}(\omega) / a$ can be obtained. A non-linear fit procedure is then applied to the experimental $Q_{\mathrm{abs}}(\omega) / a$ spectrum to determine the $3 \mathrm{~N}$ values of the oscillator parameters $\left(\omega_{j}, \gamma_{j}, F_{j}\right)$ in Eq. (6). Once estimated, the $3 \mathrm{~N}$ parameters are used to calculate the dielectric function of the grain material relative to the matrix, $\bar{\varepsilon}(\lambda)$, by applying Eq. (5). The absolute dielectric function of the grain material $\varepsilon_{\mathrm{g}}(\lambda)=\varepsilon_{\mathrm{g}}^{\prime}-i \varepsilon_{\mathrm{g}}^{\prime \prime}$ is then estimated by multiplying $\bar{\varepsilon}(\lambda)$ by $\varepsilon_{\mathrm{m}}$. Finally, the spectral real, $n_{\mathrm{g}}(\lambda)$, and imaginary, $k_{\mathrm{g}}(\lambda)$, parts of the grain material complex refractive index can be determined using the following equations:

$n_{\mathrm{g}}=\left(\frac{1}{2}\left[\sqrt{\left(\varepsilon_{\mathrm{g}}^{\prime}\right)^{2}+\left(\varepsilon_{\mathrm{g}}^{\prime \prime}\right)^{2}}+\varepsilon_{\mathrm{g}}^{\prime}\right]\right)^{1 / 2}$.
$k_{\mathrm{g}}=\left(\frac{1}{2}\left[\sqrt{\left(\varepsilon_{\mathrm{g}}^{\prime}\right)^{2}+\left(\varepsilon_{\mathrm{g}}^{\prime \prime}\right)^{2}}-\varepsilon_{\mathrm{g}}^{\prime}\right]\right)^{1 / 2}$.

The real and imaginary parts of both the dielectric function and refractive index are not independent quantities. They are related through the Kramers-Kronig relations, which for the refractive index can be written as

$n_{\mathrm{g}}(\omega)-1=\frac{2}{\pi} P \int_{0}^{\infty} \frac{\Omega \cdot k(\Omega)}{\Omega^{2}-\omega^{2}} \cdot d \Omega$,
$k_{\mathrm{g}}(\omega)=-\frac{2 \omega}{\pi} P \int_{0}^{\infty} \frac{n(\Omega)}{\Omega^{2}-\omega^{2}} \cdot d \Omega$,

where $P$ is the Cauchy principal value of the integral. It should be noticed that the retrieval method based on the Lorentzian dispersion theory used here allows one to obtain $\left(\varepsilon_{\mathrm{g}}^{\prime}, \varepsilon_{\mathrm{g}}^{\prime \prime}\right)$ and $\left(n_{\mathrm{g}}, k_{\mathrm{g}}\right)$ couples which automatically satisfy the Kramers-Kronig relations.

\subsection{Dust mineralogical composition}

Different techniques have been combined to yield the most complete characterization of the composition of mineral dust, including (i) wavelength dispersive X-ray fluorescence 
(WD-XRF, Panalytical PW-2404 spectrometer) to determine the dust elemental composition (Na, Mg, Al, Si, P, K, Ca, $\mathrm{Ti}, \mathrm{Fe}$ ); (ii) X-ray diffraction (XRD, Siemens D500 diffractometer) to estimate the particles' mineralogical composition in terms of clays (kaolinite, illite, smectite, chlorite), quartz, calcium-rich species (calcite, dolomite, gypsum), and feldspars (orthose, albite); (iii) the citrate-bicarbonatedithionite method (CBD, Lafon et al., 2004) to determine the dust iron oxide content; and (iv) the X-ray absorption near edge structure (XANES) and extended X-ray absorption fine structure (EXAFS) to retrieve the iron speciation between hematite and goethite. The details of the experimental protocols and data treatment for the different techniques are extensively discussed in Caquineau et al. (1997, 2002), Lafon et al. (2004), Klaver et al. (2011), and Formenti et al. (2008, 2014). The full set of analyses mentioned above has been carried out on the SOP0-47, SOP1-8, and SOP1-17 Banizoumbou samples. Instead, for the N32 and N93 Tamanrasset samples only XRD measurements have been possible.

Starting from these measurements, the dust mineralogical composition for the different samples has been estimated through the procedure described in Appendix B.

\subsection{Dust particle size distributions}

The particle number size distribution between 0.3 and $20 \mu \mathrm{m}$ on 15 size channels was measured at the two sampling sites by means of a Grimm OPC (Grimm Inc., model 1.108) (Heim et al., 2008) operated at 1 min (Tamanrasset) and 5 min (Banizoumbou) time resolutions. The Grimm OPC was factory calibrated with monodisperse polystyrene sphere latex (PSL), whose complex refractive index at the instrument operating wavelength $(780 \mathrm{~nm})$ is $1.59-0 i$. We have corrected the measured sphere-equivalent optical diameter in a sphere-equivalent geometrical diameter by taking into account the complex refractive index of the sampled aerosol (Liu and Daum, 2000). The optical-to-geometric diameter conversion has been done by recalculating the calibration curve considering the refractive index of dust aerosol. Optical calculations have been performed using the Mie theory for spherical particles. The complex refractive index was set at 1.53-0.002i, within the range of values available in the literature for Saharan dust (e.g. Osborne et al., 2008; Petzold et al., 2009). After refractive index correction the diameter measurements range for the Grimm 1.108 became $0.38-$ $28.9 \mu \mathrm{m}$.

The average of the size distribution data measured corresponding to each of the five dust filter samplings has been calculated. Continuous Grimm data were available for the three Banizoumbou SOP dust events, whereas Tamanrasset measurements were acquired only at the end of the dust episode for N32 (26 July 2006 from 10:00 to 14:17 UTC) and at the beginning for N93 (5 October 2006 between 01:00 and 08:07 UTC).

\section{Physico-chemical properties of the selected dust cases}

Figure 1 shows the normalized number and volume size distributions obtained for the five different dust events considered in this study. All size distributions are characterized by a multimodal structure with five main modes, centred at about $<0.6,1,2.5,5$, and $12 \mu \mathrm{m}$ diameters. Because of the lower size cut of the Grimm OPC at $0.3 \mu \mathrm{m}$, the lower tail of the first mode at diameter $<0.6 \mu \mathrm{m}$ is not very well defined. N32 and N93 distributions show also an additional defined mode, centred at $\sim 25 \mu \mathrm{m}$, not present in the SOP cases. This additional mode is possibly associated with the resuspension of particles very locally at the Tamanrasset site during the dust events. In terms of number distributions, the samples show a similar particle content in the whole size range, with the exception of SOP1-8, which is richer in coarse particles (diameter $>5 \mu \mathrm{m}$ ), and N93, which presents a lower particle content in the whole diameter range $\sim 0.8-25 \mu \mathrm{m}$. For N93, this is likely due to the fact that the Grimm measured at the very early stage of the dust event, thus before the maximum of the atmospheric dust load. In order to model the behaviour of the size distribution data, multimodal lognormal fits have been performed, and the fitting curves obtained are also shown in Fig. 1. Seven lognormal modes have been necessary to fit the experimental curves. The mean of the five lognormal fitting curves obtained considering (mean_A) or discarding (mean_B) the N32 and N93 modes at $25 \mu \mathrm{m}$ has been calculated, and data are also plotted in Fig. 1.

The mineralogical composition obtained for the five dust samples is reported in Table 2 and summarized as follows: (i) SOP0-47 and N32 originated in the same source areas in north-northwestern Niger, so they are characterized by the same mineralogical composition with $\sim 89-90 \%$ of clays, $6 \%$ of quartz, and $4 \%$ of iron oxides. The only significant difference between the two is the clays partitioning, with only kaolinite and illite detected in SOP0-47, and also smectite identified as a major clay component in N32; (ii) even if sampled during a Sahelian erosion event, SOP1-17 presents a mineralogy very similar to that of SOP0 -47 and N32. This may be explained considering that SOP1-17 particles were collected more than $3 \mathrm{~h}$ after the main erosion event occurred, therefore likely after the dust plume has been deprived of its component of larger particles, rich in quartz and feldspars, due to the rapid gravitational settling process (Pye, 1987). This is also consistent with the size distribution measured for this sample. For SOP1-17, the only case for which iron speciation is available, goethite is observed to dominate over hematite ( 80 vs. $20 \%$ of the iron oxide content); (iii) SOP18 , sampled in correspondence of a strong Sahelian local erosion event, differs from all the other samples because of its low amount of clays (52\%), mainly kaolinite and illite, and enrichment in quartz $(40 \%)$ and feldspars $(3 \%)$. The high quartz content also explains the larger fraction of particles, especially of diameter larger than $\sim 10 \mu \mathrm{m}$, which account for $\sim 60 \%$ of the particle volume size distribution observed 


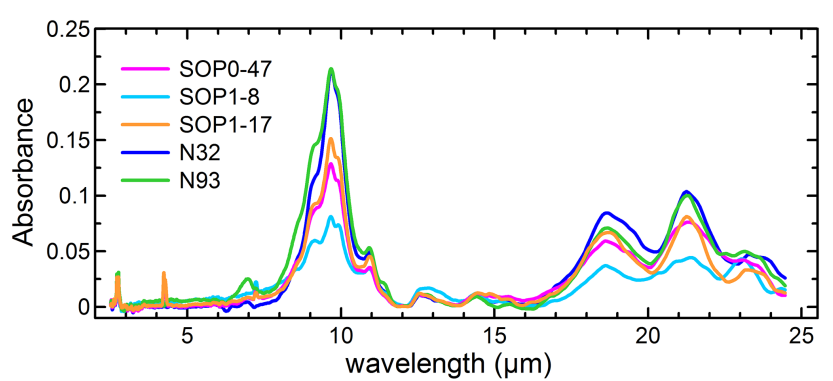

Figure 2. Absorbance spectra measured within the spectral range 2.5-25 $\mu \mathrm{m}$ for the five different dust samples. The legend identifies the line styles used in the plot.

for this sample. Finally, (iii) N93 is characterized by a lower content of clays $(67 \%)$, mainly kaolinite and smectite, together with larger amounts of quartz $(17 \%)$ and calcium-rich species (11\% of calcite and gypsum), the latter in particular indicative of northwestern Sahara source areas.

\section{Results}

\subsection{Dust infrared absorption spectra}

The absorbance spectra $\left(A=\log _{10}(1 / T)\right.$, with $T$ the transmittance) measured in the spectral range $2.5-25 \mu \mathrm{m}$ for the five different dust samples are shown in Fig. 2. The uncertainty in the measured spectra is less than $3 \%$ and has been estimated as the $3 \sigma$ variability of the signal in the regions of no dust absorption $(A<0.01)$. This uncertainty takes account of the variability of the noise and the offset components of the measured signal.

The main features of the different spectra follow the signatures of clay species (kaolinite, illite, smectite; see Fig. 3 as a reference for single mineral features and Table 3 for identified band positions and their assignments). The dust's largest absorption is observed in the window region of $8-12 \mu \mathrm{m}$ (maximum of $A$ from 0.08 to 0.21 ) and at wavelengths larger than $\sim 17 \mu \mathrm{m}$ (maximum of $A$ from 0.04 to 0.10 ), where the strongest absorption bands of clays are found. Coincident or superimposing bands for the different clay species are present at $\sim 9.0,9.7,9.9,18.8,19.3,21.4$, and $23.1 \mu \mathrm{m}$ (band peak wavelengths), while an additional single band mainly associated with kaolinite is identified in the 10.4-11.2 $\mu \mathrm{m}$ spectral region. Absorption by quartz in the atmospheric 8$12 \mu \mathrm{m}$ window region (single band at $\sim 9.2 \mu \mathrm{m}$ ) and above $17 \mu \mathrm{m}$ (two bands centred at $\sim 20$ and $22 \mu \mathrm{m}$ ) appears to be masked by the clay signals, while a more clear signature emerges at $\sim 12-13 \mu \mathrm{m}$. This is the case for the quartz-rich SOP1-8 sample which shows an enhanced absorption over this band compared to the other dust cases. The calculated ratio of the quartz band peak intensity (at $\sim 12.5 \mu \mathrm{m}$ ) between SOP1-8 and the other samples varies between a minimum of 1.32 and 1.36 for SOP1-17 and N93 between a maximum

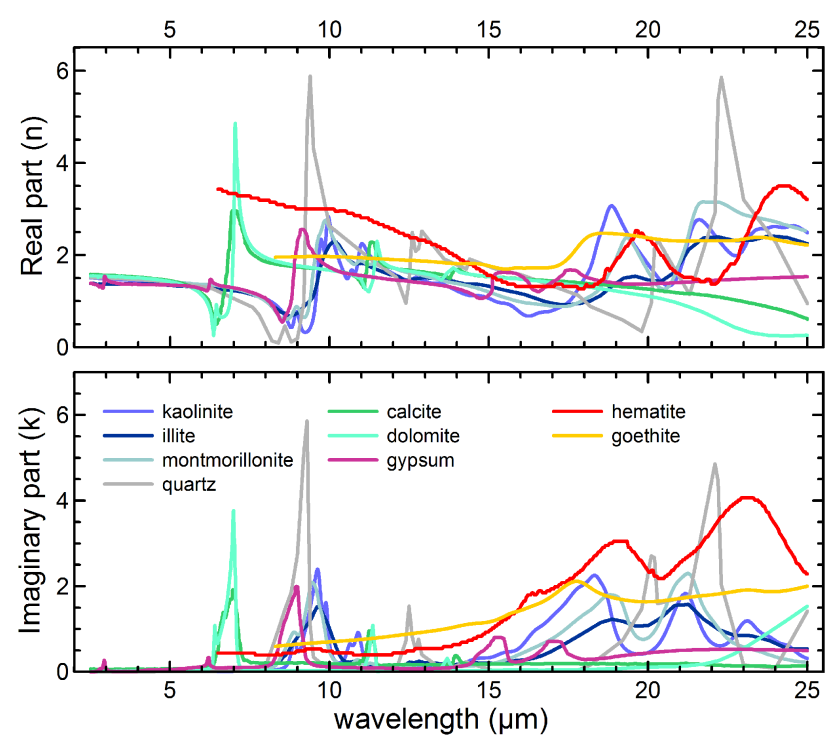

Figure 3. Real $(n)$ and imaginary $(k)$ parts of the complex refractive index within the spectral range $2.5-25 \mu \mathrm{m}$ for individual minerals composing the dust. References for the plotted curves are: kaolinite (Glotch et al., 2007), illite (Querry, 1987), montmorillonite (a mineral of the smectite family, taken here as representative for this clay species) (Glotch et al., 2007), quartz (Peterson and Weimnman, 1969), calcite (Querry et al., 1978; Long et al., 1993), dolomite (Querry, 1987), gypsum (Long et al., 1993), hematite (Marra et al., 2005), and goethite (Glotch and Rossman, 2009). No literature data are available for feldspars (orthose and albite) at infrared wavelengths. The colour code used for the different minerals is indicated in the legend in the bottom panel.

of 1.45 and 1.56 for SOP0-47 and N32, thus indicating the quartz in SOP1-8 contributes by about $30-50 \%$ to the increase in absorption in this band.

As for the quartz, the spectral signatures of the other minerals, e.g. calcium-rich species, are apparent only when the absorption of clays becomes very low. This is the case of sample N93, for which it is possible to detect the signal of calcite, at $\sim 7$ and $\sim 11.4 \mu \mathrm{m}$, and also of gypsum, whose band between 8.2 and $9.2 \mu \mathrm{m}$ appears to combine with the clays and quartz bands determining a broadening of the N93 spectrum in this part of the window spectrum. A small signature is also observed for all the different samples between 14 and $16 \mu \mathrm{m}$, possibly associated with the combined effect of calcium-rich minerals and iron oxides absorbing in this spectral interval (calcite, gypsum, hematite, goethite). The strongest signatures of iron oxides, which mainly occur at wavelengths larger than $15 \mu \mathrm{m}$ (two large bands centred at $\sim 19$ and $23 \mu \mathrm{m}$ for hematite, and one at $\sim 18 \mu \mathrm{m}$ for goethite), are instead very difficult to detect due to their superposition with clay bands.

Almost negligible differences in terms of the position of the absorption bands are observed for the different samples. Conversely, a marked sample-to-sample variability of the 
Table 2. Mineralogical composition (percentage by mass) of the five samples from the Banizoumbou and the Tamanrasset sites. The estimated uncertainties associated with the identification of the different mineral species are for clays $\pm 8-20 \%$, quartz $\pm 3 \%$, calcite $\pm 3 \%$, dolomite $\pm 10 \%$, gypsum $\pm 5 \%$, orthose $\pm 7 \%$, albite $\pm 2 \%$, and iron oxides $\pm 10-12 \%$.

\begin{tabular}{|c|c|c|c|c|c|c|c|c|c|c|c|}
\hline \multirow[t]{2}{*}{ Sample ID } & \multicolumn{3}{|c|}{ Clays } & \multirow[t]{2}{*}{ Quartz } & \multicolumn{3}{|c|}{ Calcium-rich } & \multicolumn{2}{|c|}{ Feldspars } & \multicolumn{2}{|c|}{ Iron oxides } \\
\hline & Kaolinite & Illite & Smectite & & Calcite & Dolomite & Gypsum & Orthose & Albite & Hematite & Goethite \\
\hline SOP0-47 & $81 \%$ & $8 \%$ & ND & $6 \%$ & ND & $<1 \%$ & $<1 \%$ & $<1 \%$ & $<1 \%$ & & \\
\hline SOP1-8 & $47 \%$ & $5 \%$ & ND & $40 \%$ & ND & ND & $\mathrm{ND}$ & $3 \%$ & $<1 \%$ & & \\
\hline SOP1-17 & $80 \%$ & $8 \%$ & ND & $6 \%$ & ND & ND & $\mathrm{ND}$ & $<1 \%$ & ND & $1 \%$ & $4 \%$ \\
\hline N32 & & $90 \% *$ & & $5 \%$ & $<1 \%$ & ND & $<1 \%$ & $<1 \%$ & $<1 \%$ & & \\
\hline N93 & & $67 \% *$ & & $17 \%$ & $6 \%$ & ND & $5 \%$ & $<1 \%$ & $<1 \%$ & & \\
\hline
\end{tabular}

ND - not detected.

$*$ sum of kaolinite, illite and smectite.

Table 3. Position of the main detected dust infrared band peaks with associated mineral species and transition assignment.

\begin{tabular}{rrll}
\hline $\begin{array}{r}\text { Wavelength } \\
(\mu \mathrm{m})\end{array}$ & $\begin{array}{r}\text { Wave number } \\
\left(\mathrm{cm}^{-1}\right)\end{array}$ & $\begin{array}{l}\text { Mineral } \\
\text { species }\end{array}$ & Assignment \\
\hline 2.7 & 3700 & kaolinite & OH stretching \\
2.76 & 3620 & kaolinite & OH stretching \\
7.0 & 1431 & calcite & $\left(\mathrm{CO}_{3}\right)^{2-}$ stretching \\
8.8 & 1135 & gypsum & $\mathrm{SO}_{4}$ stretching \\
9.0 & 1117 & kaolinite, smectite & $\mathrm{Si}-\mathrm{O}$ stretching \\
9.2 & 1092 & quartz & $\mathrm{Si}-\mathrm{O}$ stretching \\
9.7 & 1035 & illite, kaolinite, smectite & $\mathrm{Si}-\mathrm{O}$ stretching \\
9.9 & 1008 & kaolinite & $\mathrm{Si}-\mathrm{O}$ stretching \\
10.9 & 914 & kaolinite & $\mathrm{Al}-\mathrm{OH}$ deformation \\
11.4 & 876 & calcite & $\mathrm{C}-\mathrm{O}$ stretching \\
12.5 & 800 & quartz & $\mathrm{Si}-\mathrm{O}$ bending \\
12.9 & 777 & quartz & $\mathrm{Si}-\mathrm{O}$ bending \\
18.8 & 533 & kaolinite & $\mathrm{Fe}-\mathrm{O}$, Fe ${ }_{2} \mathrm{O}_{3}, \mathrm{Si}-\mathrm{O}-\mathrm{Al}$ stretching \\
19.3 & 519 & illite, smectite & $\mathrm{Al}-\mathrm{O}-\mathrm{Si}$ deformation \\
21.4 & 468 & illite, kaolinite, smectite & $\mathrm{Si}-\mathrm{O}-\mathrm{Si}$ bending \\
23.1 & 433 & illite, kaolinite & $\mathrm{Si}-\mathrm{O}$ deformation \\
\hline
\end{tabular}

amplitude of the band peaks is noticed. In general, the lowest absorbance is observed for SOP1-8 while highest values are obtained for N32 and N93. This is likely linked to the clay content and its speciation, as well as dust size distribution, for the different dust cases. The weaker absorption observed for SOP1-8, for instance, can be associated with the lowest illite and kaolinite content measured for this sample, thus reducing the clay mineral's absorption features. The largest absorption of N32 and N93 may be instead related, at least as a first assumption, to the presence of smectite as a dominant clay species together with kaolinite. Major absorption bands of smectite are coincident and comparable or even stronger in intensity to those of kaolinite, so the combined effect of the two clays results in an enhancement of the absorption at these wavelengths. There is also another consideration to possibly explain the larger absorption obtained for the N32 and N93 samples. As already pointed out in Sect. 3, the two Tamanrasset samples present in their size distribution a defined mode of larger particles, more efficient in interact- ing with infrared radiation, compared to the Banizoumbou samples. This means that, even with a similar mineralogical composition of dust between the two sites, we have to expect larger absorption for Tamanrasset dust due to the differences in the size distribution. This assumption can be tested, for instance, by considering the peak value of the kaolinite band at $\sim 10.9 \mu \mathrm{m}$, for which we obtain slightly larger intensities for N32 and N93 samples (0.046 and 0.05, respectively) compared to those of the SOP samples, which we know to have a similar or rather larger content of kaolinite $(0.043$ for SOP0-47 and 0.033 for SOP1-8 and SOP1-17). The role of the size distribution possibly also allows explaining the fact that sample N93, which has a global smaller content of clays but a larger fraction of coarse particles, presents an absorption which in intensity is comparable to that of the clay richer N32. The fact of observing differences in the absorption spectra which are coherent with the variability of the size distribution measured for the different samples indicates 
that the main features of dust size have changed little during sample manipulations and pellet production.

A few narrow peaks are also observed at $\sim 2.7 \mu \mathrm{m}$ for all the samples, at $\sim 4.2$ for SOP0 -47 and SOP1-17, and at $\sim 7.2 \mu \mathrm{m}$ for SOP0 -47 , SOP1-8, and SOP1-17. The peaks at 4.2 and $7.2 \mu \mathrm{m}$ are very likely due to $\mathrm{CO}_{2}$ and organic matter, respectively, which have contaminated the samples after dust- $\mathrm{KBr}$ pellet production. The intensity of these narrow peaks appears to be proportional to the absorption band of $\mathrm{H}_{2} \mathrm{O}$ observed between $\sim 2.7$ and $4 \mu \mathrm{m}$ for all the samples (not shown in the spectra of Fig. 2 because it is removed through baseline correction), which in turn is associated with the $\mathrm{KBr}$ water absorption that occurred during spectroscopic manipulations. Absorption by carbonate species (i.e. calcite) may also partly contribute to the $7.2 \mu \mathrm{m}$ band. The signal measured at $2.7 \mu \mathrm{m}$ is instead mainly related to clays (kaolinite and illite) (Saikia and Parthasarathy, 2010). These narrow peaks have been taken into account in successive analyses.

\subsection{Dust infrared complex refractive index}

Starting from the measured transmittance spectra, the $Q_{\text {abs }}(\lambda) / a$ ratio has been calculated by applying Eq. (3). The uncertainty on the calculated $Q_{\text {abs }}(\lambda) / a$, taking into account the uncertainties on the measured spectra $(<3 \%)$ and the estimated pellet dust content $(<7 \%)$, varies between a minimum of $2.4 \%$ for $\mathrm{N} 32$ to a maximum of $6.4 \%$ for SOP18. As discussed in Sect. 2.1, a non-linear fit procedure has been applied to the experimental $Q_{\text {abs }}(\lambda) / a$ to obtain the values of the $3 \mathrm{~N}$ parameters necessary to estimate the real and imaginary parts of the dust refractive index. The fitting procedure has been performed using the Levenberg-Marquardt technique (e.g. Pujol, 2007). Reasonable guesses for the oscillator parameters are manually entered as inputs, then the fitting routine returns optimized parameters. The initial number and position of oscillators is set to be equal to that of the absorption bands present in the experimental $Q_{\mathrm{abs}}(\lambda) / a$ spectrum. Additional oscillators may be subsequently added in order to improve the results of the best-fit procedure. To guarantee a successful analysis, however, the number of fitting oscillators should remain limited; furthermore, the obtained $3 \mathrm{~N}$ oscillator parameters must all have positive values (Spitzer and Kleinman, 1961; Roush et al., 1991). The experimental $Q_{\text {abs }}(\lambda) / a$ spectra together with the theoretical curves obtained from the non-linear fitting procedure are shown in Fig. 4. The number of oscillators used for each fit, also reported in the plot, is between 22 and 29. Residuals $(R)$ between the experimental and the fitted $Q_{\mathrm{abs}}(\lambda) / a$ and normalized by the measurement error have been calculated to verify the goodness of the results. An example is shown in Fig. 5, where the spectral $R$ obtained for two of the five analysed dust samples (SOP1-8 and N93) are plotted. It indicates that the $Q_{\mathrm{abs}}(\lambda) / a$ spectra are fitted within their estimated uncertainty $(|R| \leq 1)$ approximately in the entire wavelength range with significant absorbance $(A>0.01)$. Discrepancies
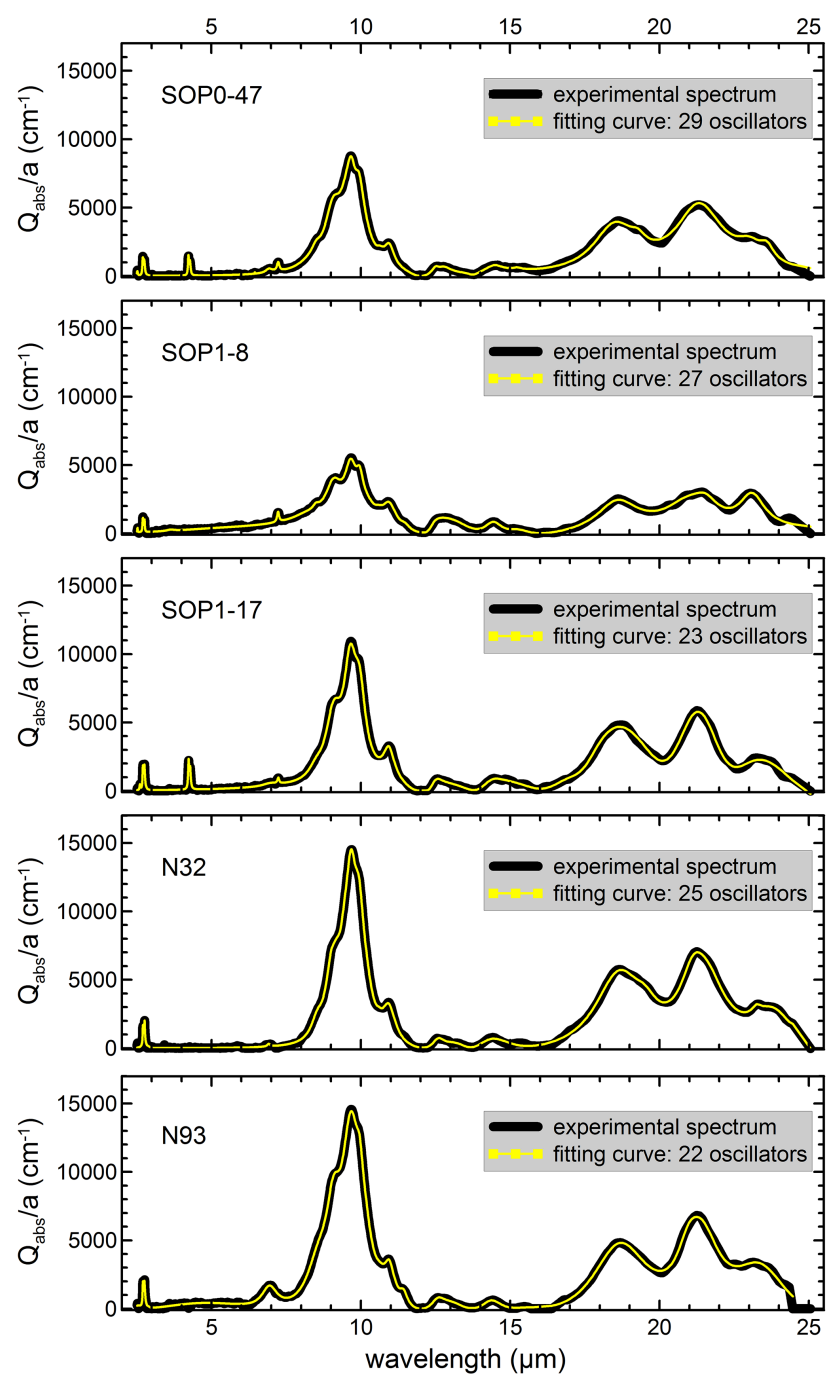

Figure 4. Comparison between the experimental $Q_{\mathrm{abs}}(\lambda) / a$ $\left(\mathrm{cm}^{-1}\right)$ spectra (black curves) and the theoretical ones obtained from the non-linear fitting procedure (yellow curves). The line styles used in the plot and the number of oscillators for each fit are also indicated in the legends.

between the experimental and the fitted curves $(|\mathrm{R}| \leq 10)$ are obtained for $\lambda<6-7 \mu \mathrm{m}$ and in a few narrow bands between 12 and $17 \mu \mathrm{m}$, thereby in spectral regions where dust absorption is close to zero. The set of $3 \mathrm{~N}$ parameters estimated from the $Q_{\text {abs }}(\lambda) / a$ fits have been used to calculate, by applying Eqs. (5) and (7), the real and the imaginary parts of the refractive index.

A sensitivity analysis was carried out in order to assign an uncertainty to the retrieved values of $n$ and $k$, whose determination is based on a minimization procedure. The sensitivity analysis is aimed at assessing how the uncertainties on the measured $Q_{\mathrm{abs}}(\lambda) / a$ affect the retrieved parameters. To this purpose, the values of $n$ and $k$ are also obtained by using as input the observed $Q_{\mathrm{abs}}(\lambda) / a$ plus or minus one 


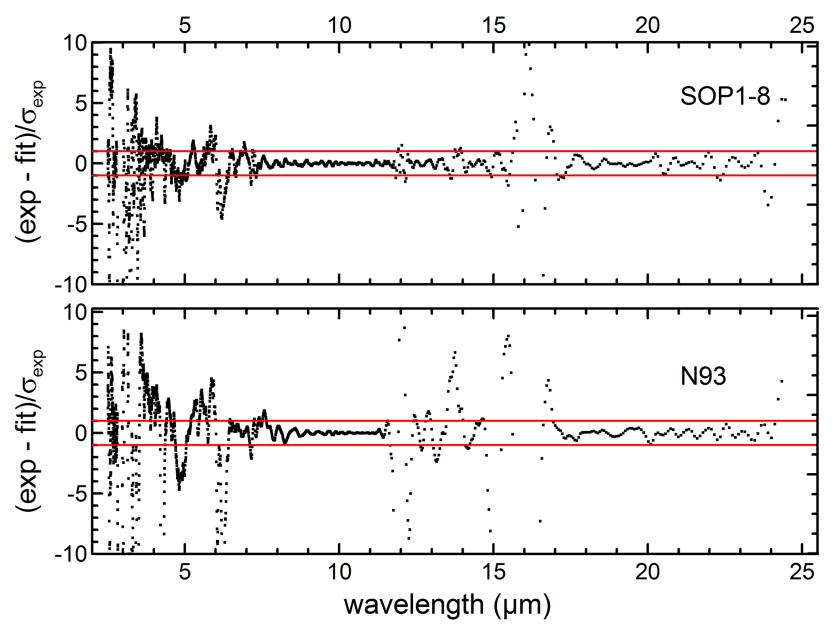

Figure 5. Residuals $\left(R=\frac{(\exp -\mathrm{fit})}{\sigma_{\exp }}\right)$ of the fit normalized by the measurement errors calculated for SOP1-8 and N93. In the residual calculation, exp is the experimental $Q_{\mathrm{abs}}(\lambda) / a$, while fit is the $Q_{\mathrm{abs}}(\lambda) / a$ obtained from the fitting procedure. The measurement error, $\sigma_{\exp }$, is $6.4 \%$ for SOP1-8 and $5.9 \%$ for N93. Red lines indicate the \pm 1 interval.

standard deviation on their measurement. The deviations of the values of $n$ and $k$ retrieved in the sensitivity study with respect to those obtained in the first inversion are assumed to correspond to the one standard deviation uncertainty. The results show the uncertainty is small $(<1.5 \%$, averaged over the whole spectral range) for the real part of the refractive index, while more significant $(<25 \%)$ for the imaginary part. Another source of uncertainty for $n$ and $k$, which we do not quantify in this study, is also associated with the choice of the $\left(n_{0, \mathrm{~m}}\right)_{\text {vis }}$ value in Eqs. (5)-(7), here set at 1.53 in agreement with past literature studies (Volz, 1973; Carlson and Benjamin, 1980; Longtin et al., 1988).

The real and the imaginary parts of the refractive index obtained for the five dust samples considered in this study are shown in Fig. 6. As expected, the retrieved $n$ and $k$ reproduce well the features detected in the absorbance spectra, both in terms of spectral signature and relative intensities between the different samples. Evident is the contribution of clays, especially in the 8-12 and 17-25 $\mu \mathrm{m}$ spectral intervals where multiple bands, reproducing the absorption due to kaolinite, illite, and smectite, are observed. The sharp transition, from low absorption outside these spectral ranges to the maximum absorption within them, determines the largest variations of the refractive index. In the $8-12 \mu \mathrm{m}$ window, the imaginary part rapidly increases from $\leq 0.001$ to peak values of 0.3 0.85 , while the real part ranges between 1.1 and 2.0. Above $17 \mu \mathrm{m}, k$ peaks at $0.45-1.0$, and $n$ varies between 1.2 and 2.7. As for the absorbance, refractive index data display a very weak quartz signature, with the only exception of the $12-13 \mu \mathrm{m}$ band, where the absorption of quartz induces an increase of $k$ to values of $\sim 0.09$ for SOP $1-8$ and $<0.06$ for
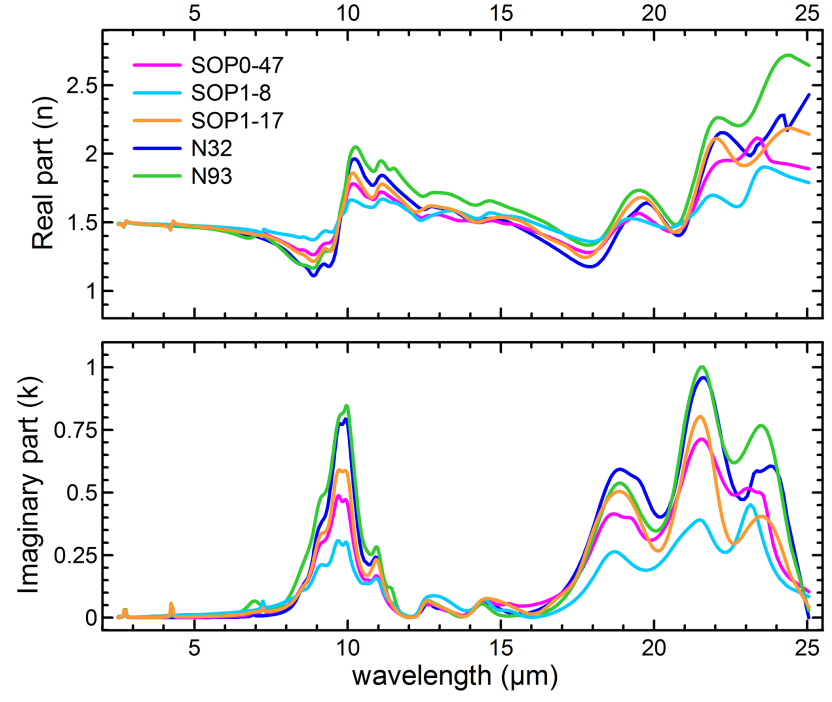

Figure 6. Real ( $n$, top panel) and imaginary ( $k$, bottom panel) parts of the complex refractive index obtained within the range $2.5-25 \mu \mathrm{m}$ for the five different dust samples. The legend in the top panel identifies the line styles used in the plot.

the other samples. The contribution of calcite to the refractive index of $\mathrm{N} 93$ is marked at $\sim 7 \mu \mathrm{m}(k \sim 0.07)$, while it is almost indistinguishable at $\sim 11.4 \mu \mathrm{m}$. Also, a refractive index comparable to that of quartz and calcite $(k \sim 0.06-0.08)$ is observed at $14-16 \mu \mathrm{m}$ due to the combination of calcite, gypsum, and iron oxides signatures.

A small red shift of less than $0.3 \mu \mathrm{m}$ (or $10 \mathrm{~cm}^{-1}$ ) is observed in correspondence of the different refractive index peaks compared to the experimental absorption spectra. This is possibly associated with the fact of using the Mie theory to reproduce dust absorption in our retrieval algorithm. Our $10 \mathrm{~cm}^{-1}$ shift is however small compared to the $25-40 \mathrm{~cm}^{-1}$ Mie-induced shift reported by several authors investigating the extinction spectra of several clay and non-clay dust constituent minerals (Hudson et al., 2008a, b; Laskina et al., 2012). This suggests the effect of shifting due to the use of the Mie theory is partly mitigated when considering the extinction spectra of dust particles instead of single minerals.

Our results show the dust refractive index to significantly vary in magnitude for the five analysed samples. For instance, within the main clay absorption bands we obtain for N32 and N93 values of $k$ which are 2-3 times larger compared to SOP1-8. Differences of up to $30-40 \%$ are also observed for the real part in the cases considered. As discussed in Sect. 4.1, this variability is linked to the variability of mineralogical composition and size distribution observed for the different dust events. In conclusion, these results, despite obtained considering aerosols from a limited number of sources from western Africa, appear rather significant as they clearly put in evidence the large sensitivity of the refractive index to the physico-chemical properties of dust particles. 


\subsection{Comparison with literature data and the OPAC database}

The results of our analysis have been compared with other studies providing direct estimates (pellet spectroscopy data on dust collected at different sites, i.e. Germany, Barbados, and Niger; Volz, 1972, 1973; Fouquart et al., 1987) and mineralogy-based calculations (Longtin et al., 1988) of the dust infrared refractive index, as well as syntheses of available literature data (Carlson and Benjamin, 1980; Sokolik et al., 1993). These studies have been selected as they serve as the main basis for models for aerosol optical properties (e.g. Toon and Pollack, 1976; Shettle and Fenn, 1976, 1979; WMO, 1986; D'Almeida, 1991) and global aerosol databases, such as OPAC and GADS, all extensively used in a wide variety of radiative and climatological studies. Besides, the OPAC aerosol database plays a very important role in satellite remote sensing as it is the most used reference for dust properties in the retrieval algorithms of several sensors measuring in the thermal infrared (MODIS, SEVIRI, AVHRR, HIRS, AIRS, IASI) (see Table 1 in Klüser et al., 2012). Owing to its widespread utilization and relevance for atmospheric application, the complex refractive index of the desert aerosol model from the OPAC database is also considered for comparison with our results.

The results of the comparison are shown in Fig. 7. For both the real and the imaginary parts, our estimates of the dust refractive index fall, over the whole considered spectrum, within the range of variability reported in literature data. For the imaginary part, a similar spectral behaviour is observed in the $8-12 \mu \mathrm{m}$ window region between our data and the different literature curves, with the only exception of Longtin et al. (1988) due to the large contribution of quartz in their calculations. The spectral signatures from the different clay species appear smoothed in the curves taken from the literature, mainly because of the rather coarse spectral resolution of these data sets. Only a major single peak between 9 and $10 \mu \mathrm{m}$ is observed, compared to our data where multiple clay peaks are detected in the $8-12 \mu \mathrm{m}$ spectral interval. The majority of the different data sets presents the signature of calcite at $\sim 7 \mu \mathrm{m}$ in the $k$ spectrum, as also observed in our data for the N93 sample. Above 11-12 $\mu \mathrm{m}$, the imaginary part of the refractive index obtained in this study is lower in magnitude compared to most of literature data at nearly all spectral bands. For the real part of the refractive index, a comparable spectral variability is obtained between our data and the different literature data sets in the $2.5-17 \mu \mathrm{m}$ spectral range, and a significant weaker variation is observed for our results in the 8-12 $\mu \mathrm{m}$ window. The best agreement, also in terms of measured intensity, is found with the real part from Volz (1972) in the whole 8-25 $\mu \mathrm{m}$ interval. For literature data, and Longtin et al. (1988) in particular, a stronger contribution of quartz is observed in both the real and the imaginary spectra, with strong peaks detected at $\sim 9.2,12.5,20$ and $22 \mu \mathrm{m}$. Furthermore, above $17 \mu \mathrm{m}$ the different data sets, with the only

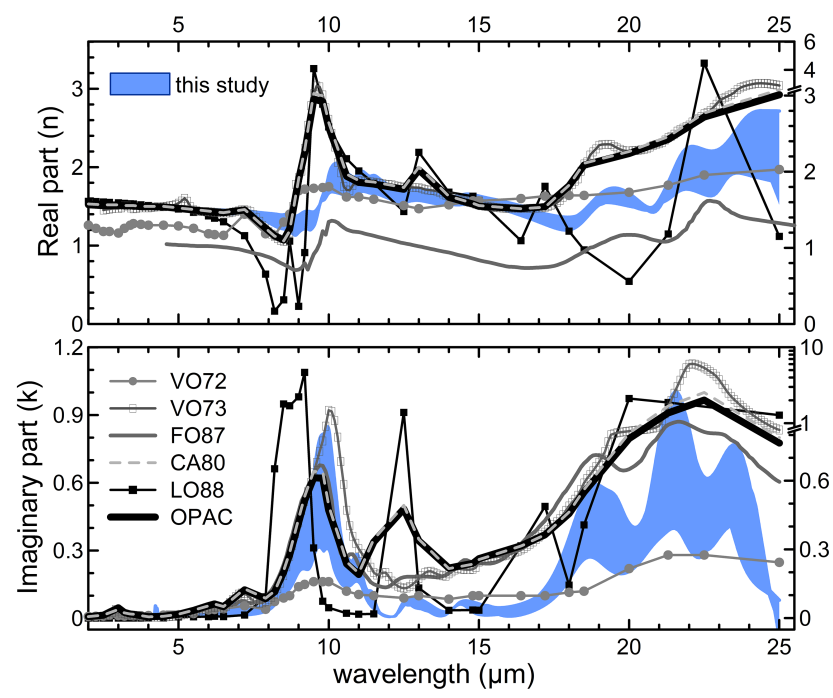

Figure 7. Comparison of our results with other direct and indirect estimates of the dust refractive index as reported in the literature. The plot reports the real and the imaginary parts of the refractive index for (1) Volz (1972) (indicated as VO72 in the plot): rainout dust aerosols collected in Germany and composed of a mixture of soil particles, fly ashes, and pollen (spectroscopy method; also used as the "dust-like" model in Shettle and Fenn, 1979). (2) Volz (1973) (indicated as VO73): Saharan dust collected at Barbados, West Indies (spectroscopy method). (3) Fouquart et al. (1987) (indicated as FO87): Saharan sand collected at Niamey, Niger (spectroscopy method). (4) Carlson and Benjamin (1980), Sokolik et al. (1993) (indicated as CA80): mineral dust model, as used in the OPAC and GADS databases (based on a synthesis of measurements on Saharan dust or generally on desert aerosols). (5) Longtin et al. (1988) (indicated as LO88): dust sand, i.e. modelled as an internal mixture of hematite ( $10 \%$ by volume) and quartz. In the internal mixing hypothesis the dust refractive index is calculated as the volume average of the refractive indices of individual minerals. (6) OPAC desert model: modelled as an internal mixture of a water soluble component at $80 \%$ relative humidity ( $5 \%$ by volume), and mineral dust in nucleation ( $3 \%$ by volume), accumulation ( $72 \%$ by volume) and coarse ( $20 \%$ by volume) modes (Hess et al., 1998); the dust refractive index for the three modes is that reported by CA80. The region in blue in the plot indicates the range of variability of the results of this study. The legend in the bottom panel identifies the line styles used in the plot for literature data. Refractive index $y$ axes are located on the left side of the plots, with the only exception of LO88 for which the $y$ axis is on the right side.

exception of Fouquart et al. (1987) and in part Volz (1973), appear to mostly not capture the signatures of clays, which instead are observed to dominate our $n$ and $k$ experimental curves.

For both the real and the imaginary parts, the ensemble of literature data and our estimates are observed to span a relative large interval of values. This variability is related, as a first hypothesis, to the fact that the different studies refer to dust from diverse source regions as well as to different stages of their atmospheric lifetime, thus to particles characterized 
by a different composition and size distribution, and thus having different optical properties. A large variability of the dust infrared refractive index has been also documented by Patterson et al. (1981) and Otto et al. (2007), who compiled literature data from additional studies. For instance, for the imaginary part they reported a range of values spanning the interval $0.02-1.0$ at $8-12 \mu \mathrm{m}$, comparable to that in Fig. 8 . Thus, the comparison between our results and literature data confirms the large variability of the dust infrared complex refractive index as a function of the physico-chemical properties of the particles.

As discussed by Sokolik et al. (1993), however, differences between the various data sets might be associated not only with the specific physico-chemical state of the particles, but also with uncertainties due to the different methods used to estimate the dust refractive index. This is, for instance, the case when comparing our data with those by Volz (1972, 1973). In these studies the real and imaginary parts of the dust refractive index were derived by two different methods: the imaginary part using transmission measurements and the real part using reflectance measurements, both with the standard pellet technique. For the imaginary part, the transmission spectra inversion was performed by applying a method which is mostly consistent with our approach, as discussed in Sect. 2.1, and this also explains the good comparison with our data for $k$. For the real part they inverted the reflectance spectra by combining the specular reflectance law and the previous estimated imaginary part of the refractive index. We found, however, that by following this procedure they obtained real and imaginary parts of the refractive index which do not verify the Kramers-Kronig relationship, and this explains why there is a larger disagreement with our results for $n$, especially in the $8-12 \mu \mathrm{m}$ window. Similar considerations are valid also for Carlson and Benjamin (1980) and OPAC data. This also implies that caution has to be used when making use of these refractive index data as, from a theoretical point of view, they are incorrect.

\section{Infrared intensive optical properties of mineral dust: variability and implications}

\subsection{Sensitivity to refractive index and size distribution}

Intensive optical properties relevant to radiative transfer (mass extinction efficiency, $k_{\text {ext }}, \mathrm{m}^{2} \mathrm{~g}^{-1}$; single scattering albedo, $\omega$; asymmetry factor, $g$ ) have been calculated for the five analysed dust samples based on their estimated complex refractive index and measured particle size distribution.

Two sets of $k_{\text {ext }}, \omega$, and $g$ have been computed: (i) at first, calculations have been performed by considering for the different samples their own complex refractive index, while fixing a unique size distribution for all the cases (i.e. the mean_B average size distribution shown in Fig. 1). This permits one to focus exclusively on the effect of refractive index variability on the estimated properties; (ii) as a second approach, the own size distribution for each of the different samples has been used together with the complex refractive index to calculate $k_{\text {ext }}, \omega$, and $g$. In this case, the combined effect of refractive index and size distribution variability will emerge from the results. In this study, we have decided to neglect the effect of particle shape (Kalashnikova and Sokolik, 2002; Nousiainen, 2009), and dust optical calculations have been performed using Mie theory for spherical particles. The ensemble of calculated dust optical properties is reported in Fig. 8. By comparison, the spectral optical properties obtained using the OPAC refractive index, calculated considering the mean_B size distribution, are also shown in the plot.

We consider at first data obtained for the fixed dust size distribution (Fig. 8a). Calculated optical properties, $k_{\text {ext }}$ and $\omega$ in particular, follow the spectral signature and variability of the complex refractive index, with the strongest absorption observed in the window region and at wavelengths $>17 \mu \mathrm{m}$. $k_{\text {ext }}$ and $\omega$ vary within the range $\sim 0.05-0.25 \mathrm{~m}^{2} \mathrm{~g}^{-1}$ and $\sim 0.25-1.0$, respectively. The asymmetry factor is observed to decrease approximately linearly with $\lambda$ for all the samples, with values ranging from a maximum of $\sim 0.75$ at $2.5 \mu \mathrm{m}$ to a minimum of 0.25 at $25 \mu \mathrm{m}$. Moderate differences are obtained between the different samples for $k_{\text {ext }}$ and $g$, while larger variations are observed for $\omega$, especially below $10 \mu \mathrm{m}$ and within the range $12-23 \mu \mathrm{m}$. In comparison to our data, the calculation based on the OPAC refractive index appears to overestimate dust extinction (up to $0.1 \mathrm{~m}^{2} \mathrm{~g}^{-1}$ increase), especially at $9-10 \mu \mathrm{m}$, mainly due to the stronger contribution of scattering for the OPAC real refractive index, and at $12-14 \mu \mathrm{m}$, for the quartz band. Absorption from OPAC is considerably larger than our estimates at the $2.5-8 \mu \mathrm{m}$ and 11-17 $\mu \mathrm{m}$ spectral ranges, with differences in $\omega$ reaching up to 0.6 at several bands. An underestimation of the dust absorption is observed in the window region between 9 and $10 \mu \mathrm{m}$, with differences in $\omega$ of up to 0.15 . When looking at the asymmetry factor, OPAC calculations appear in agreement with our results in reproducing the magnitude and the spectral decrease of $g$.

As expected, the differences between the different samples, and also between our samples and OPAC, considerably increase when the own size distribution for each case is taken into account (Fig. 8b). $k_{\text {ext }}, \omega$, and $g$ vary in this case within the range $\sim 0.05-0.35 \mathrm{~m}^{2} \mathrm{~g}^{-1}, \sim 0.25-1.0$, and $\sim 0.05-0.75$, respectively. The largest differences, compared to the results of Fig. 9a, are obtained for N93, due to the combination of a relatively high refractive index and a strong fraction of coarse particles for this sample. Significant differences can be also observed for SOP1-17, especially at $\sim 10 \mu \mathrm{m}$ and for wavelengths $<6 \mu \mathrm{m}$, mainly due to the presence of a dominant particle mode centred at $5 \mu \mathrm{m}$. SOP1-8, although very rich in coarse particles, presents, in a wide spectral range, the lowest $k_{\text {ext }}$ and highest $\omega$ (i.e. less absorption), and this is caused by the very low values of the refractive index measured for 

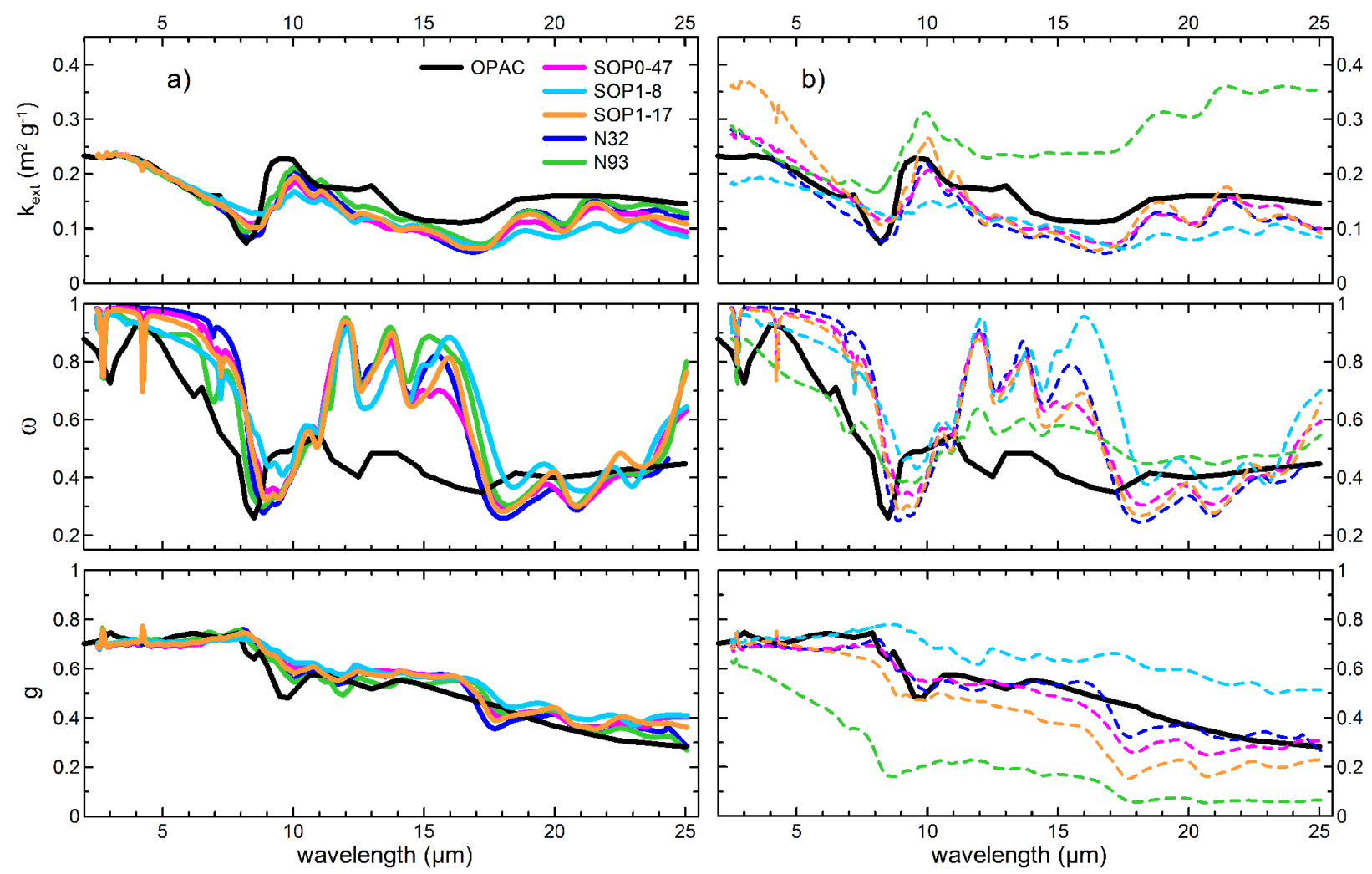

Figure 8. Mass extinction efficiency $\left(k_{\text {ext }}, \mathrm{m}^{2} \mathrm{~g}^{-1}\right)$, single scattering albedo $(\omega)$, and asymmetry factor $(g)$ computed with the Mie theory between 2.5 and $25 \mu \mathrm{m}$ for the five analysed dust cases. Calculations have been performed by considering for each sample the estimated refractive index and (a) the same size distribution for the five cases, i.e. the mean_B reported in Fig. 1, or (b) the own size distribution measured in correspondence of each sample. By comparison, the spectral optical properties obtained using the OPAC refractive index, calculated considering the mean_B size distribution, are shown in the plot. The legend in the top left panel identifies the line styles used in the plot.

this sample compared to the other dust cases. However, for the SOP1-8 sample the effect of having a dominant mode of coarse particles strongly influences $g$, for which the largest values are obtained.

The comparison of our results with those obtained in other studies is very difficult due to the large variety of refractive index and size distribution data used in the literature. McConnell et al. (2010), for instance, have estimated intensive optical properties in the spectral range of $0.2-10 \mu \mathrm{m}$ for Western Saharan dust aerosols based on internal and external mineralogy-based calculations of the refractive index and aircraft in situ measurements of the particle size distributions. Our results (Fig. 8a) for both $k_{\text {ext }}$ and $g$ appear in reasonable agreement (less than about 0.05 absolute difference in mean) with the estimates by McConnell et al. (2010), while lower values (up to 0.2 absolute value difference) are obtained in our study for the single scattering albedo in the window region. In another study, Hansell et al. (2011) have analysed the variability of $k_{\text {ext }}$ as a function of the physico-chemical properties of dust, by testing a large number of models for refractive index and particle size distribution. Their results span a relatively extended interval, with $k_{\text {ext }}$ within the $8-12.5 \mu \mathrm{m}$ spectral region varying between about 0 and $1.2 \mathrm{~m}^{2} \mathrm{~g}^{-1}$. Our results fall in the range of variability reported in that study. Hansell et al. (2011) have also shown that the differences in $k_{\text {ext }}$ due to the variability of the refractive index and size may significantly amplify when the effect of the shape of particles is considered in the optical calculations. This aspect deserves to be accounted for in future investigations.

\subsection{Implications for satellite remote sensing}

The possible impact of the variability of the dust infrared optical properties on the bands used for satellite retrievals has been investigated. The main information used by the different satellite inversion algorithms to estimate various dust parameters, such as optical depth at $10 \mu \mathrm{m}$, altitude, or effective radius, is the a priori estimate of its spectral infrared optical depth (Pierangelo et al., 2004; Klüser et al., 2011, 2012). Therefore, to test the satellite sensitivity to dust properties we have focused on the differences between our estimates of $k_{\text {ext }}$ and those based on the OPAC model in the window spectral region. The variability of the spectral mass extinction 


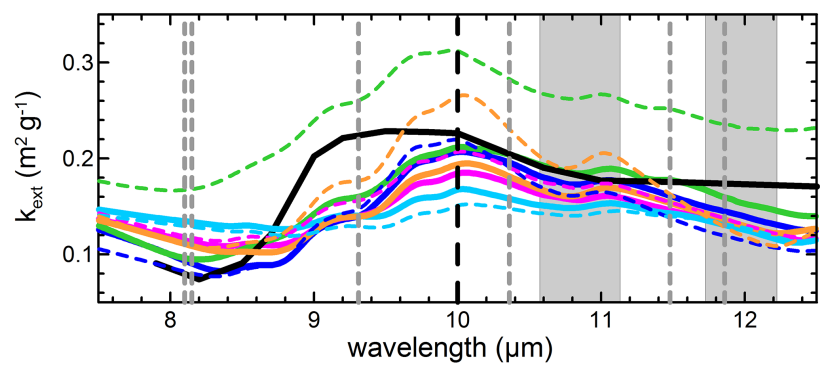

Figure 9. Mass extinction efficiency $\left(k_{\text {ext }}, \mathrm{m}^{2} \mathrm{~g}^{-1}\right)$ calculated for the five dust cases within the 7.5-12.5 $\mu \mathrm{m}$ spectral range. According to Fig. 8, continuous and dashed lines correspond to $k_{\text {ext }}$ calculations performed by considering, respectively, the same size distribution for all dust cases (continuous lines) and the own size distribution corresponding to each sample (dashed lines). Vertical lines and the two shaded areas refer to the following different satellite remote sensing channels: (grey dashed lines) six AIRS channels for dust retrieval in the thermal infrared $(8.10,8.15,9.31,10.36,11.48$, and $11.86 \mu \mathrm{m})$; (black dashed line) IASI channel for dust optical depth retrieval at $10 \mu \mathrm{m}$; and (grey shaded areas) the two MODIS broadband channels (10.78-11.28 and 11.77-12.27 $\mu \mathrm{m})$ used for sea surface temperature (SST) estimation.

coefficient is, in fact, proportional to the variability of the aerosol's spectral optical depth. The calculated $k_{\text {ext }}$ within the $8-12.5 \mu \mathrm{m}$ range is shown in Fig. 9, where also the main bands for dust retrieval in the thermal infrared from the AIRS and IASI satellites are reported. In most cases, with the exception of the channels at $\sim 8 \mu \mathrm{m}$, the OPAC $k_{\text {ext }}$ is observed to fall approximately at the mean of the ensemble of values estimated in this study. A disagreement of up to $0.1 \mathrm{~m}^{2} \mathrm{~g}^{-1}$, corresponding to $50-100 \%$ of the OPAC $k_{\text {ext }}$ absolute value, is observed with respect to the minimum and maximum of $k_{\text {ext }}$ for our samples at the different AIRS and IASI bands. Considerable differences in terms of spectral variation are also obtained between the OPAC and our experimental $k_{\text {ext }}$, especially within the $8.5-10$ and $11-12.5 \mu \mathrm{m}$ regions. The results of this simple comparison suggest that the fact of not taking into account the variability of dust properties, i.e. using the OPAC model in satellite inversion algorithms, is expected to possibly induce a significant source of uncertainty on the dust retrievals.

Dust absorption also affects the satellite retrieval of key land and atmospheric parameters. In Fig. 9, for instance, we also report the two MODIS thermal infrared broadband channels, the 31 and 32 centred at 11 and $12 \mu \mathrm{m}$, used to estimate the SST. The retrieval scheme for SST uses the estimated brightness temperature at the two channels $\left(\mathrm{BT}_{11}\right.$ and $\left.\mathrm{BT}_{12}\right)$, as well as their calculated difference $\left(\mathrm{BT}_{11}-\mathrm{BT}_{12}\right)$. The absolute value and spectral variations of $k_{\text {ext }}$ affect both quantities. The dust effect on the retrieval of $\mathrm{BT}_{11}$ and $\mathrm{BT}_{12}$ has been reported by several authors to be one of the causes for the observed bias between satellite-derived SST and surface measurements (May et al., 1992; Chan and Gao, 2005; Mer- chant et al., 2006). The OPAC model is not able to reproduce the variability of the $k_{\mathrm{ext}}$, both in terms of absolute intensity and spectral changes, therefore contributing to the uncertainties in SST estimations. For example, the integrated area of $k_{\text {ext }}$ over the 11 and $12 \mu \mathrm{m}$ MODIS bands is 0.089 and 0.087 for OPAC, compared to 0.123 and 0.110 for the maxima of $k_{\text {ext }}$ at the two bands (sample N93, green dashed line), and 0.067 and 0.054 for the corresponding $k_{\text {ext }}$ minima (samples SOP1-8, light-blue dashed line, and N32, blue dashed line). These results indicate that, with respect to our data, OPAC may underestimate, approximately by a factor 2 and an order of magnitude, respectively, the absolute intensity and the spectral variability of the dust signature at the 11 and $12 \mu \mathrm{m}$ bands, therefore contributing to the uncertainties on SST estimations.

All these considerations show the necessity of using a new optical model in place of OPAC, which is able to provide a better description of the spectral and regional variability of dust properties. The use of this new model would help increase the accuracy of satellite inversions over regions affected by the presence of dust.

\subsection{Implications for dust radiative forcing}

$k_{\text {ext }}$ data can be also used to provide a first guess approximation of the dust infrared radiative forcing sensitivity to dust properties. To do that, we have decided to focus on the forcing efficiency ( $\mathrm{FE}, \mathrm{W} \mathrm{m}^{-2} \tau^{-1}$ ) which is the key parameter describing the aerosol radiative effect. FE is defined as the ratio between the radiative forcing, generally calculated over the whole solar or infrared broadband ranges, and the aerosol optical depth, usually taken at visible wavelengths. The calculation of the forcing efficiency, with respect to the optical depth between wavelength $\lambda_{1}\left(\mathrm{FE}_{\lambda_{1}}\right)$ and the visible wavelength $\left(\mathrm{FE}_{\mathrm{vis}}\right)$, can be performed through the relation

$\mathrm{FE}_{\lambda_{1}}=\mathrm{FE}_{\mathrm{vis}} \frac{\tau_{\mathrm{vis}}}{\tau_{\lambda_{1}}}$.

The $\frac{\tau_{\mathrm{vis}}}{\tau_{\lambda_{1}}}$ term is a non-linear function of the aerosol size and refractive index, and may strongly vary as a function of the intensity of absorption bands at infrared wavelengths. Here we want to test the changes in the dust infrared FE when this is calculated with respect to the optical depth at 8,10 , and $12 \mu \mathrm{m}$. For the dust infrared forcing efficiency we have taken as a reference the mean of the cloud-free $\mathrm{FE}_{\mathrm{vis}}$ values reported by Brindley and Russell (2009) at the top of the atmosphere (TOA) for North Africa $\left(\sim 15 \mathrm{~W} \mathrm{~m}^{-2}\left(\tau^{-1}\right)_{0.55 \mu \mathrm{m}}\right)$. Calculations of $\mathrm{FE}_{8 \mu \mathrm{m}}, \mathrm{FE}_{10 \mu \mathrm{m}}$, and $\mathrm{FE}_{12 \mu \mathrm{m}}$ have been performed for samples SOP0-47, N32, and N93, for which measurements of the optical depth at $0.50 \mu \mathrm{m}$, i.e. the $\tau_{\mathrm{vis}}$, were available from AERONET data at the stations. The optical depth at 8,10 , and $12 \mu \mathrm{m}$ for SOP0-47, N32, and N93 has been calculated as the product between $k_{\text {ext }}$ (Fig. 9, dashed curves) and the column dust load, DL $\left(\mathrm{g} \mathrm{m}^{-2}\right)$, estimated for each case. DL has been retrieved as the ratio of the measured 
Table 4. Estimated dust optical depth and TOA forcing efficiency (FE, $\mathrm{W} \mathrm{m}^{-2} \tau^{-1}$ ) at 8,10 , and $12 \mu \mathrm{m}$ for the SOP0-47, N32, and N93 cases (see text for details). The measured $\tau$ at $0.50 \mu \mathrm{m}$ from AERONET is also reported.

\begin{tabular}{lc|cc|cc|cc}
\hline & & \multicolumn{2}{c|}{$8 \mu \mathrm{m}$} & \multicolumn{2}{c|}{$10 \mu \mathrm{m}$} & \multicolumn{2}{c}{$12 \mu \mathrm{m}$} \\
\cline { 2 - 8 } & $\begin{array}{c}\tau_{0.50 \mu \mathrm{m}} \\
\text { (from AERONET) }\end{array}$ & $\tau_{8 \mu \mathrm{m}}$ & $\mathrm{FE}_{8 \mu \mathrm{m}}$ & $\tau_{10 \mu \mathrm{m}}$ & $\mathrm{FE}_{10 \mu \mathrm{m}}$ & $\tau_{12 \mu \mathrm{m}}$ & $\mathrm{FE}_{12 \mu \mathrm{m}}$ \\
\hline SOP0-47 & 0.52 & 0.18 & 42.6 & 0.31 & 25.1 & 0.20 & 39.8 \\
N32 & 1.30 & 0.36 & 54.0 & 0.92 & 21.2 & 0.48 & 40.8 \\
N93 & 0.48 & 0.17 & 43.2 & 0.31 & 23.1 & 0.23 & 31.1 \\
\hline
\end{tabular}

$\tau_{0.50 \mu \mathrm{m}}$ and the $\left(k_{\text {ext }}\right)_{0.50 \mu \mathrm{m}}$, which in turn has been calculated with the Mie theory considering the measured dust size distribution and assuming a particle refractive index at $0.50 \mu \mathrm{m}$ of $1.53-0.002 i$. The $\tau_{8 \mu \mathrm{m}}, \tau_{10 \mu \mathrm{m}}$, and $\tau_{12 \mu \mathrm{m}} \mathrm{ob}-$ tained and associated FE are reported in Table 4. The dust optical depth at infrared wavelengths varies between a minimum of 0.10 to a maximum of 0.92 , with resultant $\tau_{0.50 \mu \mathrm{m}}$ to $\tau_{8 \mu \mathrm{m}}, \tau_{10 \mu \mathrm{m}}$, and $\tau_{12 \mu \mathrm{m}}$ ratios between 1.4 and 3.6. The calculated $\mathrm{FE}_{8 \mu \mathrm{m}}, \mathrm{FE}_{10 \mu \mathrm{m}}$, and $\mathrm{FE}_{12 \mu \mathrm{m}}$ are thus up to more than three times larger than $\mathrm{FE}_{0.50 \mu \mathrm{m}}$, with an estimated maximum of $54.0 \mathrm{~W} \mathrm{~m}^{-2} \tau^{-1}$. The forcing efficiency largely varies with the wavelength, and also shows an important sensitivity to the optical properties of dust. The differences of the FE for the three cases are relatively small at $10 \mu \mathrm{m}(\sim 2-$ $4 \mathrm{~W} \mathrm{~m}^{-2} \tau^{-1}$, corresponding to a 9-18\% difference), and increases at 8 and $12 \mu \mathrm{m}$ (up to $\sim 10-12 \mathrm{~W} \mathrm{~m}^{-2} \tau^{-1}$, corresponding to about a $30 \%$ difference). Hence, these results underline the significant role of the optical properties in modulating the infrared radiative impact of dust.

\section{Conclusions}

In this paper we have presented new experimental estimates of the infrared complex refractive index of African mineral dust. The particle refractive index has been derived from laboratory transmission spectra $(2.5-25 \mu \mathrm{m})$ by applying a retrieval algorithm which combines Mie and Lorentz dispersion theories. Spectroscopy measurements have been performed on five natural dust samples collected at the sites of Banizoumbou (Niger) and Tamanrasset (Algeria) during the AMMA campaign in 2006 and which originated in different Western Saharan and Sahelian source regions. Co-located in situ measurements of the dust size distribution and laboratory analyses of particle mineralogy have been considered together with spectroscopy data in order to relate the spectral features of the refractive index to the physico-chemical properties of the particles. The main results of our study may be summarized as follows:

1. For all the different samples, the measured dust absorption spectra and estimated complex refractive index are strongly sensitive to the mineralogical composition of the particles. The main features of the different spectra follow the signatures of clay species (kaolinite, illite, smectite), with the largest absorption bands observed within the $8-12$ and $17-25 \mu \mathrm{m}$ spectral regions. Within the $8-12 \mu \mathrm{m}$ window, the imaginary part rapidly increases from $\leq 0.001$ to peak values of $0.3-0.85$, while the real part ranges between 1.1 and 2.0. Above $17 \mu \mathrm{m}$, $k$ peaks at $0.45-1.0$, and $n$ varies between 1.2 and 2.7 . Absorption by quartz and other minor minerals, such as calcium-rich species, arises only when the clay signature becomes very low. Absorption by iron oxides is observed to be almost negligible, in contrast with its crucial role at solar wavelengths (Sokolik and Toon, 1999).

2. Our results show the dust refractive index to significantly vary in magnitude for the five analysed cases. Differences between maxima and minima within the main absorption bands for the different samples may reach 1.0 for $n$ and 0.6 for $k$, corresponding to $\sim 40 \%$ variability for $n$ and changes of a factor 2-3 for $k$. The variability of $n$ and $k$ is linked to the variability of particle mineralogy, mainly clay amount and speciation, and, to a lesser extent, size distribution, in particular the coarse fraction.

3. The results of this study have been compared with other direct spectroscopy estimates and indirect calculations of the infrared refractive index available in the literature and corresponding to dust collected both close to their source regions and along the path of their atmospheric transport. The comparison indicates the results of our study and literature data are comparable in magnitude. However, when related to our results, literature data appear to fail to reproduce the signatures of the main minerals, in particular clays and quartz. Furthermore, the real and the imaginary parts of the refractive index from some literature studies are found not to verify the Kramers-Kronig relations, and thus are theoretically incorrect. The comparison between our results, from western Africa, and literature data, from different locations in Europe, Africa, and the Caribbean, nonetheless, confirms the expected large spatio-temporal variability of the infrared refractive index of dust, thus highlighting the necessity for an extended systematic investigation. 
4. Aerosol intensive optical properties relevant to radiative transfer $\left(k_{\mathrm{ext}}, \omega, g\right)$ have been calculated for the five analysed dust samples based on their estimated complex refractive index and measured particle size distribution. Results indicate a strong sample-to-sample variability for dust infrared optical properties, with $k_{\text {ext }}, \omega$, and $g$ varying within the range $0.05-0.35 \mathrm{~m}^{2} \mathrm{~g}^{-1}, 0.25-$ 1.0 , and $0.05-0.75$, respectively, due to the combined changes of both the refractive index and size distribution for the different samples. This observed variability has been tested to possibly have a significant impact on satellite retrievals and dust radiative forcing estimates in the thermal infrared. For instance, in terms of radiative effect, the changes in $k_{\text {ext }}$ may determine up to $\sim 10 \mathrm{~W} \mathrm{~m}^{-2} \tau^{-1}$ variability in the dust infrared forcing efficiency. These results point out the importance of better characterizing the infrared optical properties of dust in order to more correctly evaluate their impact on the climate system.
Spectral complex refractive index data obtained in this study are made available in the Supplement for use in remote sensing and radiative transfer calculations. Due to the scarcity of information on the infrared refractive index of desert dust, this new data set constitutes an important contribution for mineral dust studies on the regional and global scales. 
Appendix A: Selection of dust events and identification of their source region

The five dust cases analysed in this study were selected based on their different origin and associated mineralogical composition. Three of them were collected at the Sahelian site of Banizoumbou and the other two at the Saharan site of Tamanrasset.

Samples were taken during different periods corresponding to the different phases of the West Africa monsoon (WAM) annual cycle and associated AMMA SOPs. For Banizoumbou, one of the dust samples was taken during winter in correspondence of the dry season (January-February 2006, AMMA SOP0; sample ID: SOP0-47), and the other two during the pre-monsoon season (June 2006, AMMA SOP1; samples ID: SOP1-8 and SOP1-17). Emission of dust from the Sahel seldom occurs during the dry season and aerosols collected at Banizoumbou in that period correspond to transport from Saharan areas (Rajot et al., 2008). The SOP0-47 case sampled during the dry season occurred on 9 February 2006. This case was associated with a mediumrange-transport event originated from the central-western part of Niger, between the Algeria-Niger and the MaliNiger frontier regions (Klaver, 2012). In contrast with the dry season, the pre-monsoon phase is characterized by a maximum in Sahelian dust emissions (Marticorena et al., 2010). Identification of erosion conditions leading to aeolian emission have been performed by combining surface wind field and aerosol mass/concentration measurements, with the data on sand grain horizontal flow obtained by means of a saltiphone installed in proximity of the sampling site station (Klaver, 2012). Two different local erosion episodes are considered from the pre-monsoon season at Banizoumbou: SOP1-8, which occurred on 4 June 2006, and SOP1-17, between 8 and 9 June 2006. The SOP1-8 event was identified as the strongest erosion episode of the entire SOP1 period at Banizoumbou, based on the measured surface wind speed $\left(>10 \mathrm{~m} \mathrm{~s}^{-1}\right.$ during the whole event, consistently above the $6 \mathrm{~m} \mathrm{~s}^{-1}$ threshold for local emission estimated by Rajot et al., 2008) and horizontal dust grain flux (peak at $\sim 700$ counts $^{-1}$ ). SOP1-17 was instead a posterosion event characterized by the advection of dust which was locally emitted at Banizoumbou $\sim 3 \mathrm{~h}$ before the sampling started.

Tamanrasset data considered here have been acquired in the second part of 2006, during the monsoon season (JulyAugust 2006, AMMA SOP2; sample ID: N32), and the end of the monsoon, during the intertropical convergence zone (ITCZ) retreat (October-November 2006; sample ID: N93). As discussed by Cuesta et al. (2008), local dust production at Tamanrasset (over the Hoggar Massif) is very low, and most aeolian dust over this area is transported from a variety of different source regions as a result of different dustlifting mechanisms (e.g. low-level jets, cold pools, or topographic flows). The event considered here in correspondence of the monsoon season over the Sahel occurred between 21 and 27 July 2006. The dust event originated at the AlgeriaNiger frontier and was caused by the succession of three cold-pool outflows generated by mesoscale convective systems (MCS). The ITD (intertropical discontinuity) organized the three cold pools in a dust front, which propagated northwards to Tamanrasset (Cuesta et al., 2009a). The N32 sample was taken only in the first part of the episode, between 23 the 24 July. The origin of the N93 post-monsoon dust event over Tamanrasset, instead, was associated with an intrusion of the sub-tropical westerly jet (STWJ) into Morocco and northwestern Algeria, which led to the formation of downslope winds along the Saharan side of Atlas Mountains. These winds induced the formation of a dust front which moved southward reaching Tamanrasset between 5 and 7 October 2006 (N93 sample taken throughout the whole event, between 5 and 7 October) (see Cuesta et al., 2008 and Supplement). For both events (during and after the monsoon season over the Sahel), the transport time from the source regions to the sampling site of Tamanrasset was estimated to be about 1 day.

\section{Appendix B: Estimation of dust mineralogical composition}

Starting from the measurements described in Sect. 2.2 (WD$\mathrm{XRF}, \mathrm{XRD}, \mathrm{CBD}, \mathrm{XANES}$, and EXAFS), the mineralogical composition of the different dust samples has been estimated through the following procedure.

First, the total dust mass (TDM) collected on the filters has been determined. For samples SOP0-47, SOP1-8, and SOP1-17, the TDM has been obtained directly from an online tapering element oscillating microbalance (TEOM, model 1400a, Rupprecht and Patashnick, Albany, USA; $5 \%$ uncertainty) available at Banizoumbou (Rajot et al., 2008). These measurements were not available at Tamanrasset. Another possible approach to estimate the TDM consists in calculating it based on the XRF-measured elemental composition. XRF analysis was not possible on N32 and N93 samples due to the high amount of dust particles deposited on the filters. We therefore considered four filters sampled immediately before and after the N32 and N93 events. For these filters, for which elemental composition was available from $\mathrm{XRF}$ analysis, the TDM was estimated as described in Formenti et al. (2014). Co-located Level 2.0 AERONET measurements at $0.50 \mu \mathrm{m}$ obtained at Tamanrasset (Cuesta et al., 2008) allowed for the estimation of an average aerosol optical depth $(\bar{\tau})$ for these cases. A linear relationship $(y=b x)$ between TDM and $\bar{\tau}$ can be established for these filters $\left(R^{2}=0.87\right)$ with $b=(3122 \pm 367) \mu \mathrm{g}$. The $b$ obtained has then been used, together with the measured $\bar{\tau}$ (see Table 1 ), to extrapolate the TDM for the N32 and N93 events. The uncertainty on the TDM obtained is $\sim 12 \%$. This procedure for the estimation of the TDM assumes the existence 
of a proportionality relation between the dust mass (sampled at the ground) and the aerosol optical depth (measured over the whole atmospheric column). This hypothesis can be considered valid at Tamanrasset, where the distribution of dust particles has been observed to be generally uniform within the Saharan atmospheric boundary layer, SABL (from a maximum altitude of $\sim 6 \mathrm{~km}$ down to the ground) (Cuesta et al., 2008, 2009b). CALIPSO (Cloud-Aerosol Lidar and Infrared Pathfinder Satellite Observation) lidar transects (http://www-calipso.larc.nasa.gov/products/lidar) passing very close to Tamanrasset in correspondence with the two considered dust events also confirm this assumption.

As a second step, the apportionment of the TDM between the different minerals has been evaluated in the following way:

1. The mass of quartz (with an uncertainty $(\sigma)$ of $\pm 3 \%$ ), calcium-rich species (calcite, $\sigma= \pm 3 \%$, dolomite, $\sigma= \pm 10 \%$, gypsum, $\sigma= \pm 5 \%$ ), and feldspars (orthose, $\sigma= \pm 7 \%$, albite, $\sigma= \pm 2 \%$ ) have been estimated, both for the Banizoumbou and the Tamanrasset samples, from XRD analysis by applying the calibration coefficients reported in Klaver et al. (2011) and Formenti et al. (2014).

2. The mass of iron oxides has been obtained from CBD $(\sigma= \pm 10 \%)$ for the SOP0-47, SOP1-8, and SOP1-17. For the N32 and N93 cases, instead, the iron oxide content has been estimated from the elemental Fe assuming the ratio between the iron in the form of oxide and the total elemental Fe to be 0.59 (Formenti et al., 2008). The Fe content of the N32 and N93 events has been calculated with a procedure similar to that used for the TDM, i.e. by performing a linear fit $(y=d x)$ of the measured $\mathrm{Fe}$ and $\bar{\tau}$ for the four dust samples obtained before and after the two considered events. The result in this case is $d=(142 \pm 18) \mu \mathrm{g}$, with a correlation $R^{2}=0.87$. The uncertainty on the iron oxide content estimated through this procedure is $\sim 12 \%$. For the SOP $1-17$ sample only, the speciation between hematite and goethite has been also determined through XANES and EXAFS analyses.
3. The mass of clays (kaolinite, illite, smectite, chlorite), which cannot be directly determined from XRD data due to the absence of appropriated calibration standards for these components, has been estimated as the difference between TDM and the total mass of quartz, calcium-rich species, feldspars, and iron oxides. The mass apportionment between the different clays species can be performed when only kaolinite (K) and illite (I) are present. In this case the mass of the two clays can be separated by the knowledge of their ratio I/K, as estimated by Caquineau et al. (2002). For SOP0-47, SOP1-8, and SOP1-17, the I/ K ratio was set at 0.1 . For the N32 and N93 samples, instead, smectite was also detected in XRD spectra and the mass apportionment between the different clay species could not be done. The uncertainty on the estimated total clay mass, calculated with the error propagation formula including the uncertainties on TDM and the other identified mineral species, varies between 8 and $20 \%$. 


\section{The Supplement related to this article is available online at doi:10.5194/acp-14-11093-2014-supplement.}

Acknowledgements. This work was supported by the Centre National des Etudes Spatiales (CNES) and by the OSU EFLUVE (Observatoire des Sciences de l'Univers, Enveloppes Fluides de la Ville à l'Exobiologie). Based on a French initiative, AMMA was built by an international scientific group and is currently funded by a large number of agencies, especially from France, the United Kingdom, the United States, and Africa. It has been the beneficiary of a major financial contribution from the European Community's Sixth Framework Research Programme. Detailed information on scientific coordination and funding is available on the AMMA International Web site at http://www.amma-international.org. The Tamanrasset AMMA supersite deployment and operation were supported by the Office National de la Météorologie (ONM) in Algeria, the Laboratoire de Météorologie Dynamique (LMD), and the Laboratoire Atmosphères, Milieux, Observations Spatiales (LATMOS). Thanks are also due to the LISA personnel who participated in field campaigns and helped with sample collection and analyses. Helpful comments and suggestions by two anonymous reviewers and the editor are also acknowledged.

Edited by: W. Lahoz

\section{References}

Ackerman, S. A.: Remote sensing aerosols using satellite infrared observations, J. Geophys. Res., 102, 17069-17080, 1997.

Ackerman, S. A. and Chung, H.: Radiative effects of airborne dust on regional energy budgets at the top of the atmosphere, J. Appl. Meteorol., 31, 223-233, 1992.

Balkanski, Y., Schulz, M., Claquin, T., and Guibert, S.: Reevaluation of Mineral aerosol radiative forcings suggests a better agreement with satellite and AERONET data, Atmos. Chem. Phys., 7, 81-95, doi:10.5194/acp-7-81-2007, 2007.

Banks, J. R. and Brindley, H. E.: Evaluation of MSG-SEVIRI mineral dust retrieval products over North Africa and the Middle East, Remote Sens. Environ., 128, 58-73, 2013.

Ben-Ami, Y., Koren, I., and Altaratz, O.: Patterns of North African dust transport over the Atlantic: winter vs. summer, based on CALIPSO first year data, Atmos. Chem. Phys., 9, 7867-7875, doi:10.5194/acp-9-7867-2009, 2009.

Ben-Ami, Y., Koren, I., Rudich, Y., Artaxo, P., Martin, S. T., and Andreae, M. O.: Transport of North African dust from the Bodélé depression to the Amazon Basin: a case study, Atmos. Chem. Phys., 10, 7533-7544, doi:10.5194/acp-10-7533-2010, 2010.

Bierwirth, E., Wendisch, M., Ehlich, A., Heese, B., Tesche, M., Althausen, D., Schladitz, A., Müller, D., Otto, S., Trautmann, T., Dinter, T., Von Hoyningen-Huene, W., and Kahn, R.: Spectral surface albedo over Morocco and its impact on radiative forcing of Saharan dust, Tellus B, 61, 252-269, 2009.

Bohren, C. E. and Huffman, D. R.: Absorption and Scattering of Light by Small Particles, Wiley, New York, 1983.

Brindley, H. E. and Russell, J. E.: An assessment of Saharan dust loading and the corresponding cloud-free longwave direct radia- tive effect from geostationary satellite observations, J. Geophys. Res., 114, D23201, doi:10.1029/2008JD011635, 2009.

Capelle, V., Chédin, A., Siméon, M., Tsamalis, C., Pierangelo, C., Pondrom, M., Crevoisier, C., Crepeau, L., and Scott, N. A.: Evaluation of IASI-derived dust aerosol characteristics over the tropical belt, Atmos. Chem. Phys., 14, 9343-9362, doi:10.5194/acp14-9343-2014, 2014.

Caquineau, S., Magonthier, M. C., Gaudichet, A., and Gomes, L.: An improved procedure for the X-ray diffraction analysis of lowmass atmospheric dust samples, Eur. J. Mineral., 9, 157-166, 1997.

Caquineau, S., Gaudichet, A., Gomes, L., and Legrand, M.: Mineralogy of Saharan dust transported over northwestern tropical Atlantic Ocean in relation to source regions, J. Geophys. Res., 107, 4251, doi:10.1029/2000JD000247, 2002.

Carlson, T. N. and Benjamin, S. T. G.: Radiative heating rates for Saharan dust, J. Atmos. Sci., 37, 193-213, 1980.

Carslaw, K. S., Boucher, O., Spracklen, D. V., Mann, G. W., Rae, J. G. L., Woodward, S., and Kulmala, M.: A review of natural aerosol interactions and feedbacks within the Earth system, Atmos. Chem. Phys., 10, 1701-1737, doi:10.5194/acp-10-17012010, 2010.

Casasanta, G., di Sarra, A. G., Meloni, D., Monteleone, F., Pace, G., Piacentino, S., and Sferlazzo, D.: Large aerosol effects on ozone photolysis in the Mediterranean, Atmos. Environ., 45, 3937 3943, 2011.

Chan, P. K. and Gao, B. J.: A comparison of MODIS, NCEP, and TMI sea surface temperature datasets, IEEE Geosci. Remote Sens., 2, 270-274, doi:10.1109/LGRS.2005.846838, 2005.

Claquin, T., Schulz, M., Balkanski, Y. J., and Boucher, O.: Uncertainties in assessing radiative forcing by mineral dust, Tellus B, 50, 491-505, 1998.

Claquin, T., Schulz, M., and Balkanski, Y. J.: Modeling the mineralogy of atmospheric dust sources, J. Geophys. Res., 104, 22243 22256, 1999.

Cuesta, J., Edouart, D., Mimouni, M., Flamant, P. H., Loth, C., Gibert, F., Marnas, F., Bouklila, A., Kharef, M., Ouchène, B., Kadi, M., and Flamant, C.: Multiplatform observations of the seasonal evolution of the Saharan atmospheric boundary layer in Tamanrasset, Algeria, in the framework of the African Monsoon Multidisciplinary Analysis field campaign conducted in 2006, J. Geophys. Res., 113, D00C07, doi:10.1029/2007JD009417, 2008.

Cuesta, J. Lavaysse, C., Flamant, C., Mimouni, M., and Knippertz, P.: Northward bursts of the West African monsoon leading to rainfall over the Hoggar Massif, Algeria, Q. J. Roy. Meteor. Soc., 136, 174-189, doi:10.1002/qj.439, 2009a.

Cuesta, J., Marsham, J. H., Parker, D. J., and Flamant, C.: Dynamical mechanisms controlling the vertical redistribution of dust and the thermodynamic structure of the West Saharan atmospheric boundary layer during summer, Atmos. Sci. Let., 10, 34-42, 2009b.

D’Almeida, G. A., Koepke, P., and Shettle, E. P.: Atmospheric Aerosols: Global Climatology and Radiative Characteristics, A. Deepak Publishing, 561 pp., 1991.

DeSouza-Machado, S. G., Strow, L. L., Hannon, S. E., and Motteler, H. E.: Infrared dust spectral signatures from AIRS, Geophy. Res. Lett., 33, L03801, doi:10.1029/2005GL024364, 2006.

Di Biagio, C., di Sarra, A., and Meloni, D.: Large atmospheric shortwave radiative forcing by Mediterranean aerosol derived 
from simultaneous ground-based and spaceborne observations, and dependence on the aerosol type and single scattering albedo, J. Geophys. Res., 115, D10209, doi:10.1029/2009JD012697, 2010.

di Sarra, A., Di Biagio, C., Meloni, D., Monteleone, F., Pace, G., Pugnaghi, S., and Sferlazzo, D.: Shortwave and longwave radiative effects of the intense Saharan dust event of March 25-26, 2010, at Lampedusa (Mediterranean sea), J. Geophys. Res., 116, D23209, doi:10.1029/2011JD016238, 2011.

Dufresne, J.-L., Gautier, C., Ricchiazzi, P., and Fouquart, Y.: Longwave scattering effects of mineral aerosols, J. Atmos. Sci., 59, 1959-1966, 2002.

Fisher, K.: The optical constants of atmospheric aerosol particles in the 7.5-12 $\mu \mathrm{m}$ spectral region, Tellus, XXVIII, 266-274, 1976.

Formenti, P., Rajot, J. L., Desboeufs, K., Caquineau, S., Chevaillier, S., Nava, S., Gaudichet, A., Journet, E., Triquet, S., Alfaro, S., Chiari, M., Haywood, J., Coe, H., and Highwood, E.: Regional variability of the composition of mineral dust from western Africa: Results from the AMMA SOP0/DABEX and DODO field campaigns, J. Geophys. Res., 113, D00C13, doi:10.1029/2008jd009903, 2008.

Formenti, P., Schütz, L., Balkanski, Y., Desboeufs, K., Ebert, M., Kandler, K., Petzold, A., Scheuvens, D., Weinbruch, S., and Zhang, D.: Recent progress in understanding physical and chemical properties of African and Asian mineral dust, Atmos. Chem. Phys., 11, 8231-8256, doi:10.5194/acp-11-8231-2011, 2011.

Formenti, P., Caquineau, S., Desboeufs, K., Klaver, A., Chevaillier, S., Journet, E., and Rajot, J. L.: Mapping the physicochemical properties of mineral dust in western Africa: mineralogical composition, Atmos. Chem. Phys., 14, 10663-10686, doi:10.5194/acp-14-10663-2014, 2014.

Fouquart, Y., Bonnel, B., Brogniez, G., Buriez, J. C., Smith, L., and Morcrette, J. J.: Observations of Sahara aerosols: Results of ECLATS field experiment. Part II: Broadband radiative characteristics of the aerosols and vertical radiative flux divergence, $\mathrm{J}$. Clim. Appl. Meteorol., 26, 38-52, 1987.

Fratini, G., Ciccioli, P., Febo, A., Forgione, A., and Valentini, R.: Size-segregated fluxes of mineral dust from a desert area of northern China by eddy covariance, Atmos. Chem. Phys., 7, 2839-2854, doi:10.5194/acp-7-2839-2007, 2007.

Ginoux, P., Prospero, J. M., Gill, T. E., Hsu, N. C., and Zhao, M.: Global-scale attribution of anthropogenic and natural dust sources and their emission rates based on MODIS Deep Blue aerosol products, Rev. Geophys., 50, RG3005, doi:10.1029/2012RG000388, 2012.

Glotch, T. D. and Rossman, G. R.: Mid-infrared reflectance spectra and optical constants of six iron oxide/oxyhydroxide phases, Icarus, 204, 663-671, 2009.

Glotch, T. D., Rossman, G. R., and Aharonson, O.: Mid-infrared $(5-100 \mu \mathrm{m})$ reflectance spectra and optical constants of ten phyllosilicate minerals, Icarus, 192, 604-622, 2007.

Gomes, L. and Gillette, D. A.: A comparison of characteristics of aerosol from dust storms in central Asia with soil-derived dust from other regions, Atmos. Environ. A-Gen., 27, 2539-2544, 1993.

Hansell Jr., R. A., Reid, J. S., Tsay, S. C., Roush, T. L., and Kalashnikova, O. V.: A sensitivity study on the effects of particle chemistry, asphericity and size on the mass extinction efficiency of mineral dust in the earth's atmosphere: from the near to thermal
IR, Atmos. Chem. Phys., 11, 1527-1547, doi:10.5194/acp-111527-2011, 2011.

Haywood, J., Francis, P., Osborne, S., Glew, M., Loeb, N., Highwood, E., Tanré, D., Myhre, G., Formenti, P., and Hirst, E.: Radiative properties and direct radiative effect of Saharan dust measured by the C-130 aircraft during SHADE: 1 . Solar spectrum, J. Geophys. Res., 108, 8577, doi:10.1029/2002JD002687, 2003.

Haywood, J. M., Allan, R. P., Slingo, T., Milton, S., Edwards, J., and Clerbaux, N.: Can desert dust explain the outgoing longwave radiation anomaly over the Sahara during July 2003?, J. Geophys. Res., 110, D05105, doi:10.1029/2004JD005232, 2005.

Heim, M., Mullins, B. J., Umhauer, H., and Kasper, G.: Performance evaluation of three optical particle counters with an efficient "multimodal" calibration method, J. Aerosol Sci., 39, 1019-1031, 2008.

Heinold, B., Tegen, I., Schepanski, K., and Hellmuth, O.: Dust radiative feedback on Saharan boundary layer dynamics and dust mobilization, Geophys. Res. Lett., 35, L20817, doi:10.1029/2008GL035319, 2008.

Hess, M., Koepke, P., and Schult, I.: Optical properties of aerosols and clouds: The software package OPAC, B. Am. Meteorol. Soc, 79, 831-844, 1998.

Highwood, E. J., Haywood, J. M., Silverstone, M. D., Newman, S. M., and Taylor, J. P.: Radiative properties and direct effect of Saharan dust measured by the C-130 aircraft during Saharan Dust Experiment (SHADE): 2. Terrestrial spectrum, J. Geophys. Res., 108, 8578, doi:10.1029/2002JD002552, 2003.

Hsu, N. C., Herman, J. R., and Weaver, C. J.: Determination of radiative forcing of Saharan dust using combined TOMS and ERBE data, J. Geophys. Res., 105, 20649-20661, doi:10.1029/2000JD900150, 2000.

Hudson, P. K., Gibson, E. R., Young, M. A., Kleiber, P. D., and Grassian, V. H.: Coupled infrared extinction and size distribution measurements for several clay components of mineral dust aerosol, J. Geophys. Res., 113, D01201, doi:10.1029/2007JD008791, 2008a.

Hudson, P. K., Young, M. A., Kleiber, P. D., and Grassian, V. H.: Coupled infrared extinction spectra and size distribution measurements for several non-clay components of mineral dust aerosol (quartz, calcite, and dolomite), Atmos. Environ., 42, 5991-5999, doi:10.1016/j.atmosenv.2008.03.046, 2008b.

Huneeus, N., Chevallier, F., and Boucher, O.: Estimating aerosol emissions by assimilating observed aerosol optical depth in a global aerosol model, Atmos. Chem. Phys., 12, 4585-4606, doi:10.5194/acp-12-4585-2012, 2012.

Israelevich, P. L., Levin, Z., Joseph, J. H., and Ganor, E.: Desert aerosol transport in the Mediterranean region as inferred from the TOMS aerosol index, J. Geophys. Res., 107, 4572, doi:10.1029/2001jd002011, 2002.

Iwasaka, Y., Shi, G.-Y., Shen, Z., Kim, Y. S., Trochkin, D., Matsuki, A., Zhang, D., Shibata, T., Nagatani, M., and Nakata, H.: Nature of atmospheric aerosols over the desert area in the Asian continent: chemical state and number concentration of particles measured at Dunhuang, China, Water Air Soil Poll., 3, 129-145, 2003.

Kalashnikova, O. V. and Sokolik, I. N.: Importance of shapes and compositions of wind-blown dust particles for remote sensing at solar wavelengths, Geophys. Res. Lett., 29, 10, 1398, doi:10.1029/2002GL014947, 2002. 
Kandler, K., Schütz, L., Deutscher, C., Ebert, M., Hofmann, H., Jäckel, S., Jaenicke, R., Knippertz, P., Lieke, K., Massling, A., Petzold, A., Schladitz, A., Weinzierl, B., Wiedensohler, A., Zorn, S., and Weinbruch, S.: Size distribution, mass concentration, chemical and mineralogical composition and derived optical parameters of the boundary layer aerosol at Tinfou, Morocco, during SAMUM 2006, Tellus B, 61, 32-50, doi:10.1111/j.16000889.2008.00385.x, 2009.

Kishcha, P., Alpert, P., Barkan, J., Kirchner, I., and Machenhauer, B.: Atmospheric response to Saharan dust deduced from ECMWF reanalysis (ERA) temperature increments, Tellus B, 55, 901-913, 2003.

Klaver, A.: Estimation des propriétés optiques des poussières désertiques d'origines saharienne et sahélienne, à proximité de leurs zones sources d'émission, à partir de leurs propriétés physicochimiques, PhD thesis, Université Paris VII, 2012.

Klaver, A., Formenti, P., Caquineau, S., Chevaillier, S., Ausset, P., Calzolai, G., Osborne, S., Johnson, B., Harrison, M., and Dubovik, O.: Physico-chemical and optical properties of Sahelian and Saharan mineral dust: in situ measurements during the GERBILS campaign, Q. J. Roy. Meteor. Soc., 137, 1193-1210, doi:10.1002/qj.889, 2011.

Klüser, L. and Holzer-Popp, T.: Relationships between mineral dust and cloud properties in the West African Sahel, Atmos. Chem. Phys., 10, 6901-6915, doi:10.5194/acp-10-6901-2010, 2010.

Klüser, L., Martynenko, D., and Holzer-Popp, T.: Thermal infrared remote sensing of mineral dust over land and ocean: a spectral SVD based retrieval approach for IASI, Atmos. Meas. Tech., 4, 757-773, doi:10.5194/amt-4-757-2011, 2011.

Klüser, L., Kleiber, P., Holzer-Popp, T., and Grassian, V. H.: Desert Dust Observation From Space - Application of Measured Mineral Component Infrared Extinction Spectra, Atmos. Environ., 54, 419-427, 2012.

Koepke, P., Hess, M., Schult, I., and Shettle, E. P.: Global aerosol dataset, Report N 243, Max-Plank-Institut für Meteorologie, Hamburg, 44 pp., 1997.

Lafon, S., Rajot, J. L., Alfaro, S. C., and Gaudichet, A.: Quantification of iron oxides in desert aerosol, Atmos. Environ., 38, 12111218, 2004.

Laskina, O., Young, M. A., Kleiber, P. D., and Grassian, V. H.: Infrared extinction spectra of mineral dust aerosol: Single components and complex mixtures, J. Geophys. Res., 117, D18210, doi:10.1029/2012JD017756, 2012.

Laurent, B., Marticorena, B., Bergametti, G., Léon, J. F., and Mahowald, N. M.: Modeling mineral dust emissions from the Sahara desert using new surface properties and soil database, J. Geophys. Res., 113, D14218, doi:10.1029/2007jd009484, 2008.

Legrand, M., Plana-Fatto, A., and N'Doumé, C.: Satellite detection of dust using the IR imagery of Meteosat1. Infrared difference dust index, J. Geophys. Res., 106, 18251-18274, 2001.

Levin, Z. and Lindberg, J. D.: Size distribution, chemical composition and optical properties of urban and desert aerosols in Israel, J. Geophys. Res., 84, 6941-6950, 1979.

Liu, Y. and Daum, P.: The effect of refractive index on size distributions and light scattering coefficients derived from optical particle counters, J. Aerosol Sci., 31, 945-957, 2000.

Long, L. L., Querry, M. R., Bell, R. J., and Alexander, R. W.: Optical properties of calcite and gypsum in crystalline and powdered form in the infrared and far-infrared, Infrared Phys., 34, 191-201, 1993.

Longtin, D. R., Shettle, E. P., Hummel, J. R., and Pryce, J. D.: A Wind Dependent Desert Aerosol Model: Radiative Properties, AFGL-TR-88-0112, Air Force Geophysics Laboratory, Hanscom AFB, MA, 1988.

Maring, H., Savoie, D. L., Izaguirre, M. A., McCormick, C., Arimoto, R., Prospero, J. M., and Pilinis, C.: Aerosol physical and optical properties and their relationship to aerosol composition in the free troposphere at izana, tenerife, canary islands, during July 1995, J. Geophys. Res.-Atmos., 105, 14677-14700, 2000.

Maring, H., Savoie, D. L., Izaguirre, M. A., Custals, L., and Reid, J. S.: Mineral dust aerosol size distribution change during atmospheric transport, J. Geophys. Res., 108, 8592, doi:10.1029/2002jd002536, 2003.

Marra, A. C., Blanco, A., Fonti, S., Jurewicz, A., and Orofino, V.: Fine hematite particles of Martian interest: absorption spectra and optical constants, J. Phys. Conf. Ser., 6, 132-138, 2005.

Marticorena, B. and Bergametti, G.: Modeling the atmospheric dust cycle: 1. Design of a soil-derived dust emission scheme, J. Geophys. Res., 100, 16415-16430, doi:10.1029/95jd00690, 1995.

Marticorena, B., Chatenet, B., Rajot, J. L., Traoré, S., Coulibaly, M., Diallo, A., Koné, I., Maman, A., NDiaye, T., and Zakou, A.: Temporal variability of mineral dust concentrations over West Africa: analyses of a pluriannual monitoring from the AMMA Sahelian Dust Transect, Atmos. Chem. Phys., 10, 8899-8915, doi:10.5194/acp-10-8899-2010, 2010.

Marzo, G. A., Blanco, A., De Carlo, F., D’Elia, M., Fonti, S., Marra, A. C., Orofino, V., and Politi, R.: The Optical constants of gypsum particles as analog of Martian sulfates, Adv. Space Res., 33, 2246-2251, 2004.

May, D. A., Stowe, L. L., Hawkins, J. D., and McClain, E. P.: A correction for Saharan dust effects on satellite sea surface temperature measurements, J. Geophys. Res., 97, 3611-3619, doi:10.1029/91JC02987, 1992.

McConnell, C. L., Formenti, P., Highwood, E. J., and Harrison, M. A. J.: Using aircraft measurements to determine the refractive index of Saharan dust during the DODO Experiments, Atmos. Chem. Phys., 10, 3081-3098, doi:10.5194/acp-10-30812010, 2010.

Merchant, C. J., Embury, O., Le Borgne, P., and Bellec, B.: Saharan dust in nighttime thermal imagery: Detection and reduction of related biases in retrieved sea surface temperature, Remote Sens. Environ., 104, 15-30, doi:10.1016/j.rse.2006.03.007, 2006.

Mishchenko, M. I., Liu, L., Travis, L. D., and Lacis, A. A.: Scattering and radiative properties of semi-external versus external mixtures of different aerosol types, J. Quant. Spectrosc. Ra., 88, 139-147, 2004.

Mooney, T. and Knacke, R. F.: Optical constants of chlorite and serpentine between 2.5 and $50 \mu \mathrm{m}$, Icarus, 64, 493-502, 1985.

Nousiainen, T.: Optical modeling of mineral dust particles: A review, J. Quant. Spectrosc. Ra., 110, 1261-1279, 2009.

Orofino, V., Blanco, A., Fonti, S., Proce, R., and Rotundi, A.: The infrared optical constants of limestone particles and implications for the search of carbonates on Mars, Planet. Space Sci., 46, 1659-1669, 1998.

Osborne, S. R., Johnson, B. T., Haywood, J. M., Baran, A. J., Harrison, M. A. J., and McConnell, C. L.: Physical and optical properties of mineral dust aerosol during the Dust and 
Biomass-burning Experiment, J. Geophys. Res., 113, D00C03, doi:10.1029/2007jd009551, 2008.

Otto, S., de Reus, M., Trautmann, T., Thomas, A., Wendisch, M., and Borrmann, S.: Atmospheric radiative effects of an in situ measured Saharan dust plume and the role of large particles, Atmos. Chem. Phys., 7, 4887-4903, doi:10.5194/acp-7-4887-2007, 2007.

Patterson, E. M.: Optical Properties of the Crustal Aerosol Relation to Chemical and Physical Characteristics, J. Geophys. Res., 86, 3236-3246, 1981.

Peterson, J. T. and Weinman, J. A.: Optical properties of quartz dust particles at infrared wavelengths, Geophys. Res. Lett., 74, 69476952, 1969.

Petzold, A., Rasp, K., Weinzierl, B., Esselborn, M., Hamburger, T., Dörnbrack, A., Kandler, K., Schötz, L., Knippertz, P., Fiebig, M., and Virkkula, A.: Saharan dust absorption and refractive index from aircraft-based observations during SAMUM 2006, Tellus B, 61, 118-130, doi:10.1111/j.1600-0889.2008.00383.x, 2009.

Pierangelo, C., Chédin, A., Heilliette, S., Jacquinet-Husson, N., and Armante, R.: Dust altitude and infrared optical depth from AIRS, Atmos. Chem. Phys., 4, 1813-1822, doi:10.5194/acp-41813-2004, 2004.

Prospero, J. M., Ginoux, P., Torres, O., Nicholson, S. E., and Gill, T. E.: Environmental characterization of global sources of atmospheric soil dust identified with the Nimbus 7 Total Ozone Mapping Spectrometer (TOMS) absorbing aerosol product, Rev. Geophys., 40, 2-1-2-31, 2002.

Pujol, J.: The solution of nonlinear inverse problems and the Levenberg-Marquardt method, Geophysics, 72, W1-W16, doi:10.1190/1.2732552, 2007.

Pye, K.: Aeolian Dust and Dust Deposits, Academic Press, London, 334 pp., 1987.

Querry, M.: Optical Constants of Minerals and Other Materials from the Millimeter to the Ultraviolet, Report CRDEC-CR-88009, US Army, Aberdeen, 1987.

Querry, M. R., Osborne, G., Lies, K., Jordon, R., and Coveney, R. M.: Complex refractive index of limestone, Appl. Optics, 17, 353-356, 1978

Rajot, J. L., Formenti, P., Alfaro, S., Desboeufs, K., Chevaillier, S., Chatenet, B., Gaudichet, A., Journet, E., Marticorena, B., Triquet, S., Maman, A., Mouget, N., and Zakou, A.: AMMA dust experiment: An overview of measurements performed during the dry season special observation period (SOP0) at the Banizoumbou (Niger) supersite, J. Geophys. Res., 113, D00C14, doi:10.1029/2008jd009906, 2008.

Redelsperger, J.-L., Thorncroft, C. D., Diedhiou, A., Lebel, T., Parker, D. J., and Polcher, J.: African Monsoon Multidisciplinary Analysis: An International Research Project and Field Campaign, B. Am. Meteorol. Soc., 87, 1739-1746, doi:10.1175/BAMS-87-12-1739, 2006.

Reid, E. A., Reid, J. S., Meier, M. M., Dunlap, M. R., Cliff, S. S., Broumas, A., Perry, K., and Maring, H.: Characterization of African dust transported to Puerto Rico by individual particle and size segregated bulk analysis, J. Geophys. Res., 108, 8591, 10.1029/2002jd002935, 2003.

Rosenfeld, D., Rudich, Y, and Lahav, R.: Desert dust suppressing precipitation: A possible desertification feedback loop, P. Natl. Acad. Sci. USA, 98, 5975-5980, doi:10.1073/pnas.101122798, 2001.
Roush, T., Pollack, J., and Orenberg, J.: Derivation of midinfrared (5-25 $\mu \mathrm{m})$ optical constants of some silicates and palagonite, Icarus, 94, 191-208, 1991.

Saikia, B. and Parthasarathy, G.: Fourier Transform Infrared Spectroscopic Characterization of Kaolinite from Assam and Meghalaya, Northeastern India, J. Mod. Phys., 1, 206-210, 2010.

Schütz, L., Jaenicke, R., and Pietrek, H.: Saharan dust transport over the North Atlantic Ocean, Spec. Pap. Geol. Soc. Am., 186, 87100, 1981.

Shettle, E. P. and Fenn, R. W.: Models of the atmospheric aerosols and their optical properties, in AGARD Conference Proceedings n. 183, Optical Propagation in the Atmosphere. Presented at the Electromagnetic Wave Fropagation Panel Symposium. Lyngby, Denmark, 27-31 October 1975. AGARD-CP-183, available from US National Technical Information Service, AD A028615, 1976.

Shettle, E. P. and Fenn, R. W.: Models for the Aerosols of the Lower Atmosphere and the Effects of Humidity Variations on Their Optical Properties, AFGL-TR-79-0214, ADA085951, 1979.

Slingo, A., Ackerman, T. P., Allan, R. P., Kassianov, E. I., McFarlane, S. A., Robinson, G. J., Barnard, J. C., Miller, M. A., Harries, J. E., Russell, J. E., and Dewitte, S.: Observations of the impact of a major Saharan dust storm on the atmospheric radiation balance, Geophys. Res. Lett., 33, L24817, doi:10.1029/2006GL027869, 2006.

Sokolik, I. N.: The spectral radiative signature of windblown mineral dust: Implications for remote sensing in the thermal IR region, Geophys. Res. Lett., 29, 2154, doi:10.1029/2002GL015910, 2002.

Sokolik, I. N. and Toon, O. B.: Direct radiative forcing by anthropogenic airborne mineral aerosols, Nature, 381, 681-683, doi:10.1038/381681a0, 1996.

Sokolik, I. and Toon, O.: Incorporation of mineralogical composition into models of the radiative properties of mineral aerosol from UV to IR wavelengths, J. Geophys. Res., 104, 9423-9444, 1999.

Sokolik, I. N., Andronova, A., and Johnson, T. C.: Complex refractive index of atmospheric dust aerosols, Atmos. Environ A-Gen.., 27, 2495-2502, 1993.

Sokolik, I. N., Toon, O. B., and Bergstrom, R. W.: Modeling the radiative characteristics of airborne mineral aerosols at infrared wavelengths, J. Geophys. Res., 103, 8813-8826, 1998.

Spitzer, W. G. and Kleinman, D. A.: Infrared lattice bands of quartz, Phys. Rev., 121, 1324-1335, 1961.

Textor, C., Schulz, M., Guibert, S., Kinne, S., Balkanski, Y., Bauer, S., Berntsen, T., Berglen, T., Boucher, O., Chin, M., Dentener, F., Diehl, T., Feichter, J., Fillmore, D., Ginoux, P., Gong, S., Grini, A., Hendricks, J., Horowitz, L., Huang, P., Isaksen, I. S. A., Iversen, T., Kloster, S., Koch, D., Kirkevåg, A., Kristjansson, J. E., Krol, M., Lauer, A., Lamarque, J. F., Liu, X., Montanaro, V., Myhre, G., Penner, J. E., Pitari, G., Reddy, M. S., Seland, Ø., Stier, P., Takemura, T., and Tie, X.: The effect of harmonized emissions on aerosol properties in global models an AeroCom experiment, Atmos. Chem. Phys., 7, 4489-4501, doi:10.5194/acp-7-4489-2007, 2007.

Toon, O. B. and Pollack, J. B.: A global average model of atmospheric aerosols for radiative transfer calculations, J. Appl. Meteorol., 15, 225-246, 1976. 
Volz, F. E.: Infrared refractive index of atmospheric aerosol substances, Appl. Optics, 11, 755-759, 1972.

Volz, F. E.: Infrared optical constants of ammonium sulfate, Sahara dust; volcanic pumice and flyash, Appl. Optics, 12, 564-568, 1973.

Wang, H., Shi, G., Li., S., Li., W., Wang, B., and Huang, Y.: The impact of optical properties on radiative forcing due to dust aerosols, Adv. Atmos. Sci., 23, 431-441, 2006.
World Meteorology Organization (WMO) publication, World Climate Research Program: A preliminary cloudless standard atmosphere for radiation computation, WCP-112, WMO/TD-NO. 24, 1986.

Winfield, K. A.: Factors controlling water retention of alluvial deposits, Western Mojave Desert, M. S. Thesis, San Jose State University, San Jose, California, 88 pp., 2000. 